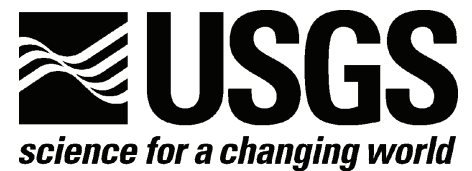

\title{
Evaluation of Some Software Measuring Displacements Using GPS in Real-Time
}

By John Langbein

2006

Open-File Report 2006-1235 


\section{U.S. Department of the Interior DIRK KEMPTHORNE, Secretary}

\section{U.S. Geological Survey \\ P. Patrick Leahy, Acting Director}

U.S. Geological Survey, Reston, Virginia 2006

For product and ordering information:

World Wide Web: http://www.usgs.gov/pubprod

Telephone: 1-888-ASK-USGS

For more information on the USGS - the Federal source for science about the Earth, its natural and living resources, natural hazards, and the environment:

World Wide Web: http://www.usgs.gov

Telephone: 1-888-ASK-USGS

Suggested citation:

Langbein, John, 2006, Evaluation of some software measuring displacement using GPS in real-time: U.S. Geological Survey Open-File Report 2006-1235, 35 p. Available on the World Wide Web at URL http://pubs.usgs.gov/of/2006/1235/ ].

Any use of trade, product, or firm names is for descriptive purposes only and does not imply endorsement by the U.S. Government. 


\section{Contents}

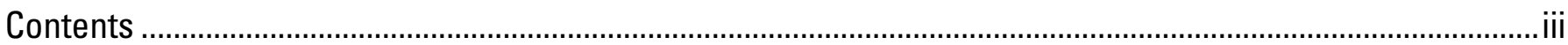

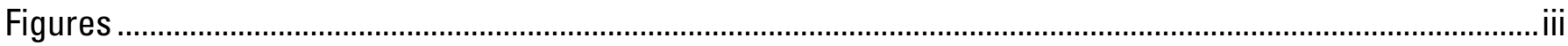

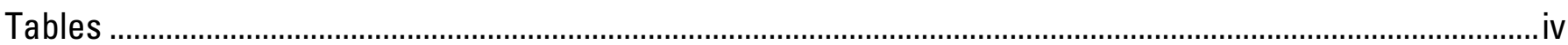

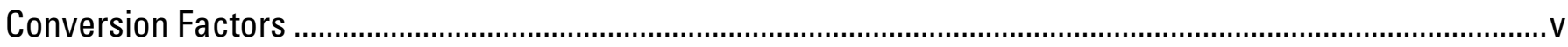

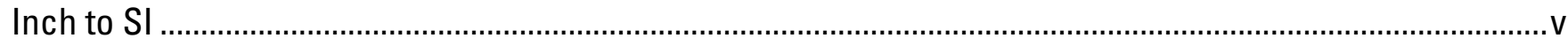

SI to Inch

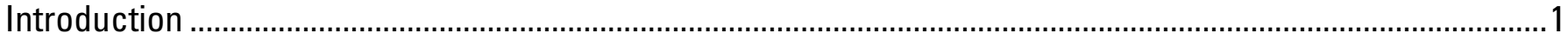

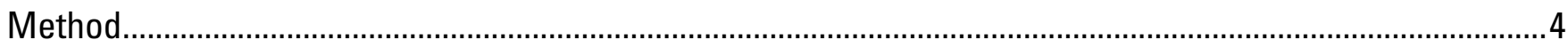

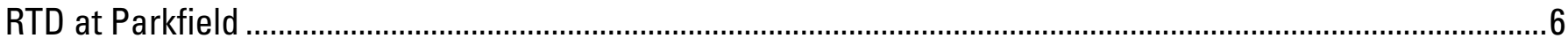

3DTracker Long Valley-Experiment 1, September 2004.................................................................10

Long Valley Experiment 2, September 2005 .............................................................................................

Long Valley Experiment 2; Replaying the data using TRACK.......................................................................22

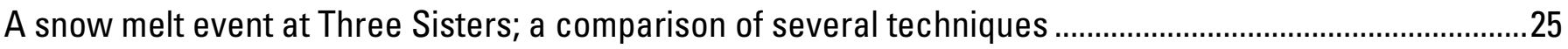

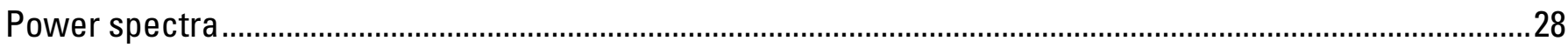

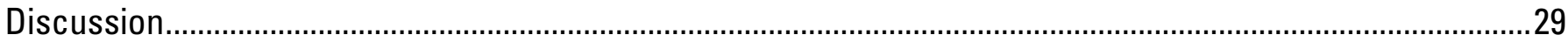

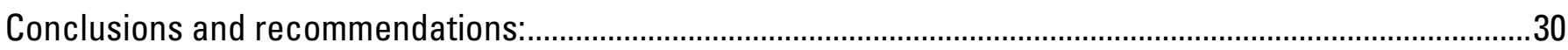

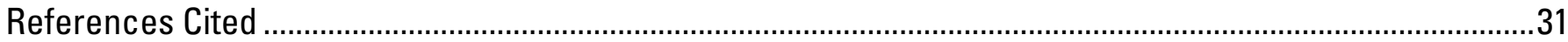

\section{Figures}

Figure 1; Experimental set up on the roof of the water treatment plant in Mammoth Lakes; the experimental set-up uses 2 tripods to hold the translation assembly. To the right is the antenna used for long term monitoring of deformation. This was disconnected from the GPS receiver and the test antenna, seen on the translation apparatus, was

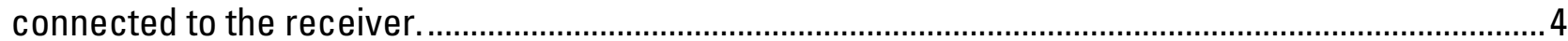

Figure 2; Experimental set up; more details of the slider and track ................................................................

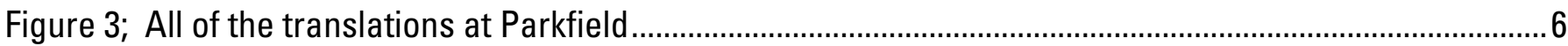

Figure 4; Details of initial translations........................................................................................................

Figure 5; details of the smaller translations..........................................................................................

Figure 6; detail of the last set of translations .............................................................................................

Figure 7; Initial set-up and all of the translations ……………………………………........................... 10

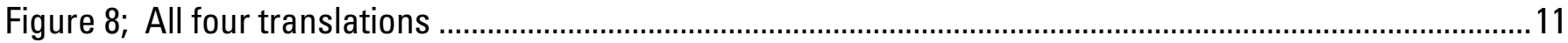

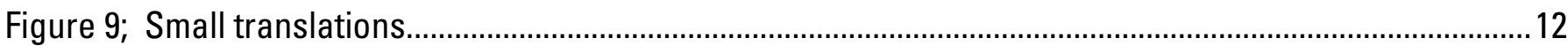

Figure 10: Displacement test to Bald; 3Dtracker; $Q=10^{\wedge}-5$; original results ................................................... 14

Figure 11: Displacement test to Tilc; $3 D$ Tracker; $Q=10^{\wedge}-05$; Original results.................................................. 14

Figure 12; Displacement test to Bald; 3DTracker; $Q=10^{\wedge}-5$; Original results for translations .......................... 15

Figure 13: Displacement test to Tilc; $3 D$ Tracker; $0=10^{\wedge}-5$; Original results for translations ............................. 16

Figure 14: Replaying BALD data through 3DTracker; compare with Figure 10............................................. 17

Figure 15; Replaying Tilc data through 3DTracker; Compare to Figure. 11 ...................................................... 18 
Figure 16; Playback of Bald data using 3 different options in 3DTracker; Kalman gain was set to 10-5. results shown are for measured offsets. .....................................................................19

Figure 17: 3DTracker results for Bald using only $L 1$ frequency but with different Kalman gains $(0) \ldots \ldots \ldots \ldots . . . .20$

Figure 18: Comparison of displacement estimated by 3DTracker (black) and TRACK (red). Left hand side is data from the entire experiment. Right hand side is data from the measured translations.

Figure 19: Comparison of displacement estimated by 3DTracker (black) and TRACK (red). Left hand side is data from the entire experiment. Right hand side is data from the measured translations. Integer ambiguities have be manually resolved in the TRACK solutions.

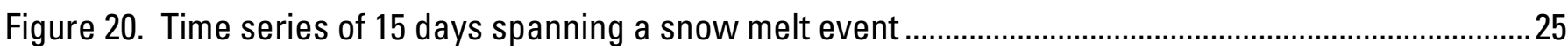

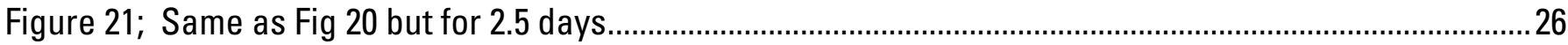

Figure 22: Power spectral density of 3DTracker data with different 0 's compared with the Parkfield data using RTD. The 0 s are arranged such that $10-5$ is on top and $10-10$ is on the bottom

\section{Tables}

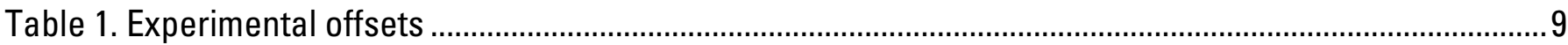

Table 2. Noise models of the data .........................................................................................................

Table 3. Statistics from translation experiments at Long Valley, September 2004.......................................... 13

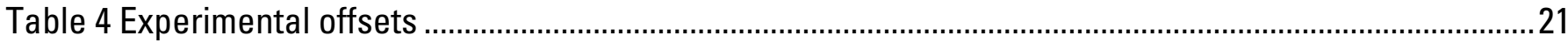

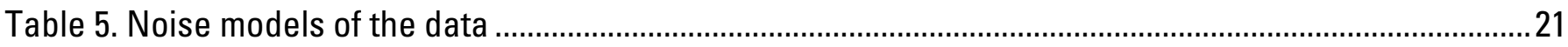

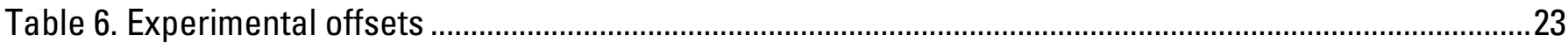

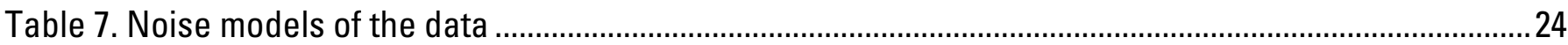




\section{Conversion Factors}

Inch to SI

\begin{tabular}{lcl}
\hline \multicolumn{1}{c}{ Multiply } & \multicolumn{1}{c}{ By } & \multicolumn{1}{c}{ To obtain } \\
\hline Length & & \\
\hline inch (in.) & 2.54 & centimeter $(\mathrm{cm})$ \\
inch (in.) & 25.4 & millimeter $(\mathrm{mm})$ \\
foot (ft) & 0.3048 & meter $(\mathrm{m})$ \\
mile (mi) & 1.609 & kilometer $(\mathrm{km})$ \\
mile, nautical (nmi) & 1.852 & kilometer $(\mathrm{km})$ \\
yard (yd) & 0.9144 & meter $(\mathrm{m})$ \\
\hline
\end{tabular}

\section{SI to Inch}

\begin{tabular}{lll}
\hline \multicolumn{1}{c}{ Multiply } & \multicolumn{1}{c}{ By } & \multicolumn{1}{c}{ To obtain } \\
\hline Length & & \\
\hline centimeter $(\mathrm{cm})$ & 0.3937 & inch (in.) \\
millimeter (mm) & 0.03937 & inch (in.) \\
meter (m) & 3.281 & foot (ft) \\
kilometer (km) & 0.6214 & mile (mi) \\
kilometer (km) & 0.5400 & mile, nautical (nmi) \\
meter (m) & 1.094 & yard (yd) \\
\hline
\end{tabular}




\title{
Evaluation of some software measuring displacements using GPS in Real-time
}

\author{
By John Langbein'
}

\section{Introduction}

For the past decade, the USGS has been monitoring deformation at various locations in the western United States using continuous GPS. The main focus of these measurements are estimates of displacement averaged over one day. Essentially, these consist of recording at 30 seconds intervals the carrier-frequency phase-data (equivalent to travel-time) between a GPS receiver and the GPS satellite network. In turn, these observations, which are converted to pseudo-ranges, are processed using one of the "research grade" programs (GIPSY, Zumberge et al., or GAMIT, wwwgpsg.mit.edu/ simon/gtgk) to estimate the position of the GPS receiver averaged over 24 hours. However, it is possible and desirable to estimate the position of the receiver (actually the antenna) more frequently and to do this within a few seconds of the time actual measurement (known as real-time). A recent example, the 2004 Magnitude 6, Parkfield, California earthquake, demonstrated that having GPS estimates of position more frequently than simply a daily average is required if one requires discrimination between co-seismic and post-seismic deformation (Langbein et al., 2006). The high-rate estimates of position obtained at Parkfield show that post-seismic deformation started less than one-hour after the mainshock and that this deformation was roughly the same magnitude as the co-seismic deformation. The high-rate solutions for Parkfield were done by others including Yehuda Bock at UCSD and Kristine Larson at U. of Colorado, but not the USGS.

The Parkfield experience points out the need for an in-house capability by the USGS to be able to accurately measure co-seismic displacements and other rapid, deformation signals using GPS. This applies to both the Earthquake and Volcano Hazard programs. Although at many locations where we monitor deformation, we have strainmeters and tiltmeters in addition to GPS which, in principle, are far more sensitive to rapid deformation over periods of less than a day (Langbein and Bock, 2004). But, not all locales include strain and tiltmeters. Thus, having the capability to extract signals with periods of less than a day is desirable since the distribution of GPS is more extensive than strain and tilt.

At both Parkfield and Long Valley, the USGS has been using other software packages to process the GPS data at sub-daily intervals and in real-time. The underlying goal of these types of measurements is to detect any deformation event as it evolves; the 24 hour processing might not provide timely results if such a deformation event is precursory to a geologic hazard (an earthquake for Parkfield and either a volcanic event or an earthquake for Long Valley).

In Long Valley, We use the software package called 3DTracker (http://www.3dtracker.com, http://www.condorearth.com) to estimate the changes of in position of a remote site relative to a

345 Middlefield RD, MS-977, Menlo Park, CA 94025 
"fixed" site. The 3DTracker software uses double difference GPS code measurements and receiversatellite-time triple differences from one epoch to the next of the GPS phase data (a proxy for travel-time measurements) and employs a Kalman filter to obtain stability in the estimate of position. That is, the estimate of the current position depends upon the estimate of the prior position. Hence, a time series of position looks fairly smooth depending upon the coefficient selected for the Kalman filter. With triple differences, the sometimes troublesome initial integer cycle ambiguity terms cancel (number of wavelengths between the receiver and each satellite), but only the incremental change in position is calculated. This triple difference Kalman filter solution is slow to converge and less accurate than a double difference (e.g., RTD, Track) solution, but it is robust and computationally efficient (Remondi and Brown, 2000). 3D-Tracker allows use of various single-frequency and dual-frequency GPS phase and code observables including the ionospheric-free combinations (known as LC or L3 and P(L3)) formed from an linear combination of the L1 and L2 carrier phase and code data. The lowest noise observable is the L1 carrier, but it is biased by ionospheric refraction that has amplitudes of about 1 to $10 \mathrm{ppm}$. This results in a systematic scale error in the relative positions. The L3 phase noise is about 3 times greater than the L1 phase noise, but it is generally used to solve for all but the shortest baselines $(<5 \mathrm{~km})$. In addition, the software does output the position changes is a standard format that can be used for other analysis.

At Parkfield, we use the software package called RTD (http://www.geodetics.com). The RTD software has been described in the literature (Bock et al., 2000) but basically, it estimates the position without the constraint of a Kalman filter. It uses double differences (in our studies the LC or ionospheric free observable is used) and the integer ambiguities are resolved independently for each 1-second measurement; Most GPS software that use double-differences require several epochs of measurements to resolve the integer ambiguities. The data files use a proprietary format and can not be read by me or others; rather, Yehuda Bock at UCSD (and author of RTD) translates these files into a standard format that can be read by me.

Recently, Tom Herring of MIT has modified the GAMIT software to process kinematically GPS data (www-gpsg.mit.edu/ simon/gtgk/tutorial/Lecture_13.pdf). At this time, the software, known as TRACK, does not process the observations in real-time. Consequently, the latency between the time of the observation and the time when a position estimate is available depends upon the frequency that the data are downloaded and the speed of actually processing the observations; there could be a delay of an hour or two before the a position estimates are available. Unlike RTD and 3DTracker, TRACK comes with GAMIT (which is distributed freely) and is currently operating in a test mode at the USGS office in Pasadena. The LC or ionosphere free observable is used in our TRACK solutions.

JPL has a version of their GIPSY software called "Real-time GIPSY (RTG)" (gipsy.jpl.nasa.gov/orms/rtg), which, like TRACK, can process the pseudo-range data "off_line". However, this software is not freely distributed. Instead, at least one company, NAVCOM, has teamed with JPL to integrate RTG with GPS receivers and telemetry that yields positions in realtime.

Kristine Larson of University of Colorado has modified the original GIPSY to estimate positions kinematically. Again, like TRACK, the positions are estimated off-line. Much of her research is described in Larson et al. (2003), and Choi et al. (2004).

For Long Valley, out of the 17 GPS sites, we monitor 5 baselines within the caldera at 5 second intervals relative to the Bald Mountain site at the edge of the caldera using 3DTracker. The baseline measurement using 3DTracker consists of determination of the 3 dimensional positions of the 5 remote points (GPS receivers) relative to a GPS site at Bald. A second, independent system 
collects and downloads once a day the 30-second data used for the 24-hour solutions for the 12 sites not monitored with 3DTracker. For the sites monitored with 3DTracker, the pseudo-range data are decimated to 30 seconds and converted to a form used for the 24-hour solutions. Both sets of telemetry employ $900 \mathrm{MHz}$ spread spectrum radios which require line of site between all of the links. The telemetry for the 3DTracker sites require a dedicated radios at each end and intermediate repeaters as needed, while the telemetry required for the other sites use a single master radio, repeaters as needed, and a radio at each remote site. (The 5 sites being monitored with 3DTracker require 13 radios.)

At Parkfield, RTD is used to measure the position changes all 12 baselines at 1 second intervals relative to a site, Pomm, adjacent to the San Andreas Fault. The complete RTD package (hardware and software) collects all of the data and determines the position of each site relative to Pomm. In addition, the system stores both the 1-second and 30-second pseudo-range data for later downloading which are ultimately used in the 24-hour solutions. To do this, each site has a $2.4 \mathrm{GHz}$ radio and a telemetry buffer. The telemetry buffer holds 24-hours of data (in the event that the telemetry link is broken) and converts the RS232 data stream from the GPS receiver into a form compatible with an IP (Internet protocol) network connection. In contrast with the Long Valley system, the telemetry link for GPS at Parkfield consists of a single radio at each remote sites and a single radio at the central site. Although position estimates are produced within 1-second of the observations, these results are not immediately available because there is no high speed Internet connection to Parkfield. Instead, the data are stored on a removable disk and sent to UCSD once per month.

Below, I describe the results of a simple experiment to examine the response of some of these systems to simulated deformation that could be an analogue of a tectonic or volcanic event. In many engineering applications, the system response is tested by inputting a step to the system and measuring the output of the system. Essentially, this is what I've done. The experiment described below moves the GPS antenna from its original position to a new position within 1 second; the software tracks the translation. These measurements were conducted in August 2004 with the RTD software at Parkfield, and twice in Long Valley. The first Long Valley test was conducted in September 2004 using 3DTracker on a single baseline. The test was repeated in September 2005 using 3DTracker on two baselines and, importantly, saving the RINEX files of the data so that the data could be replayed through 3DTracker using other options in the program and, using other software packages including TRACK.

In addition, we observed a short-term event at the Three Sisters volcano in Oregon. This event was snow melt at a remote GPS site which gave an apparent $15 \mathrm{~cm}$ displacement in vertical in less than one-day. 3DTracker is used to monitor this site, and the event was captured with this software. In addition, with the assistance of others, I got additional estimates of position using other software packages; those results are presented.

Finally, the precision of both 3DTracker and RTD are compared using a power spectrum. Those results would suggest that 3DTracker using appropriate Kalman filter coefficients would have better precision than RTD; instead, the lower noise level from 3DTracker is a result of smoothing from the Kalman filter.

Given the results described in this report, high-rate GPS is certainly capable of accurately measuring displacements of 1 centimeter with a high degree of statistical confidence. Plotting these results show that the time of the displacement can be visually determined to that of the sampling interval of the data. However, especially with small amplitude signals, any of the software packages can yield erroneous deformation "signals" that are either due excess travel-time of the GPS carrier frequency from multipath or a limitation in the software. Thus, the time series of 
displacements must be viewed with caution and knowledge of external circumstances that might cause a change in position.

The casual reader should continue with the next section describing the methods then jump to the last two sections for the discussion and conclusions. I have made some recommendations there

\section{Method}

The basic method is to move the GPS antenna on a controlled path quickly and to record the change of its position with time. This is facilitated by using a slider on a 1 meter long rail positioned between two tripods. This setup is shown for the experiment on the roof top at the sewer plant in Mammoth Lakes (Long Valley). The picture shows two tripods, the rail and slider assembly, and the GPS antenna without the SCIGN dome. To the right of the setup is the GPS antenna that is used for the normal monitoring at this site (Mwtp) in Long Valley.

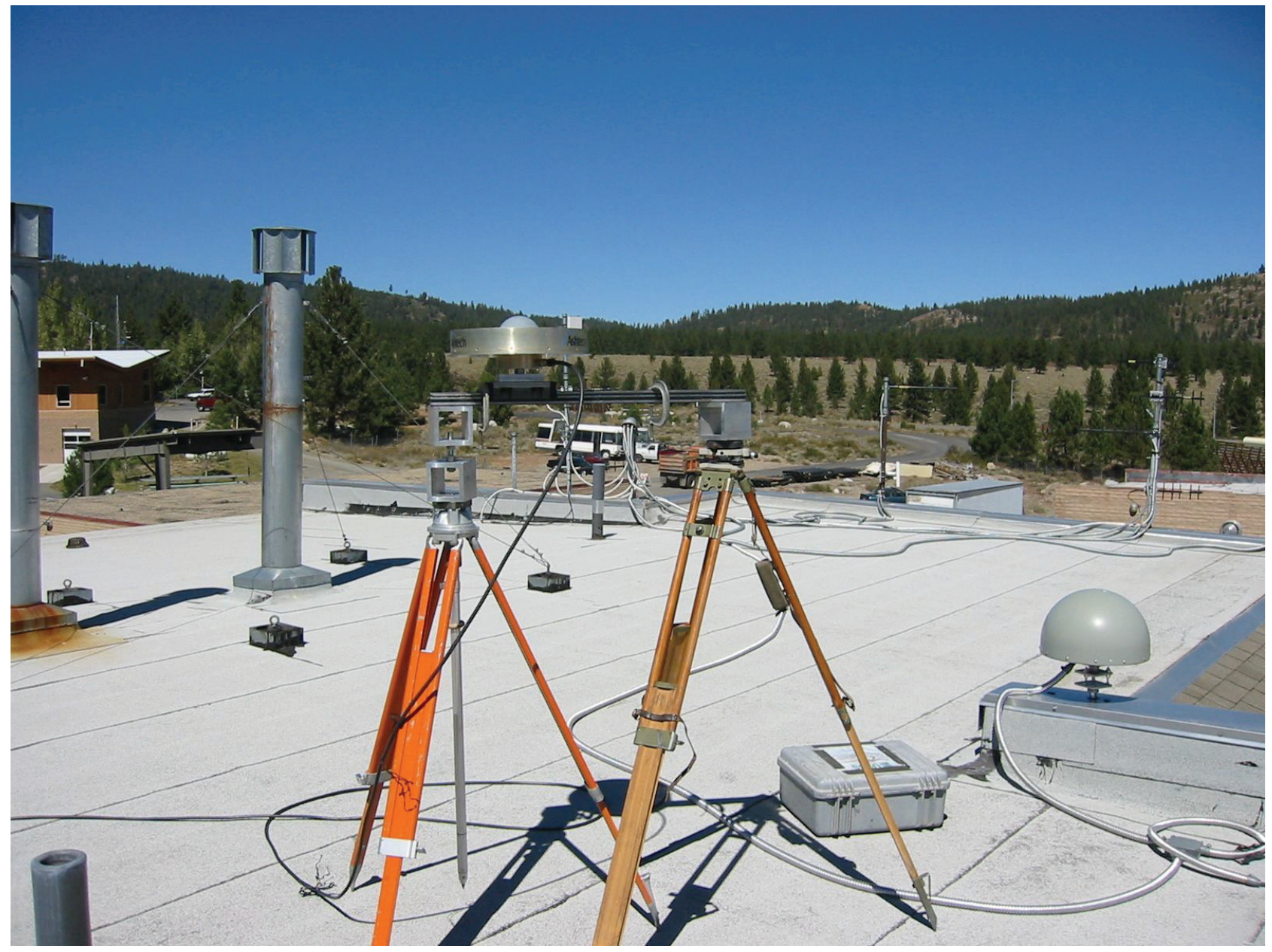

Figure 1; $\quad$ Experimental set up on the roof of the water treatment plant in Mammoth Lakes; the experimental set-up uses 2 tripods to hold the translation assembly. To the right is the antenna used for long term monitoring of deformation. This was disconnected from the GPS receiver and the test antenna, seen on the translation apparatus, was connected to the receiver. 


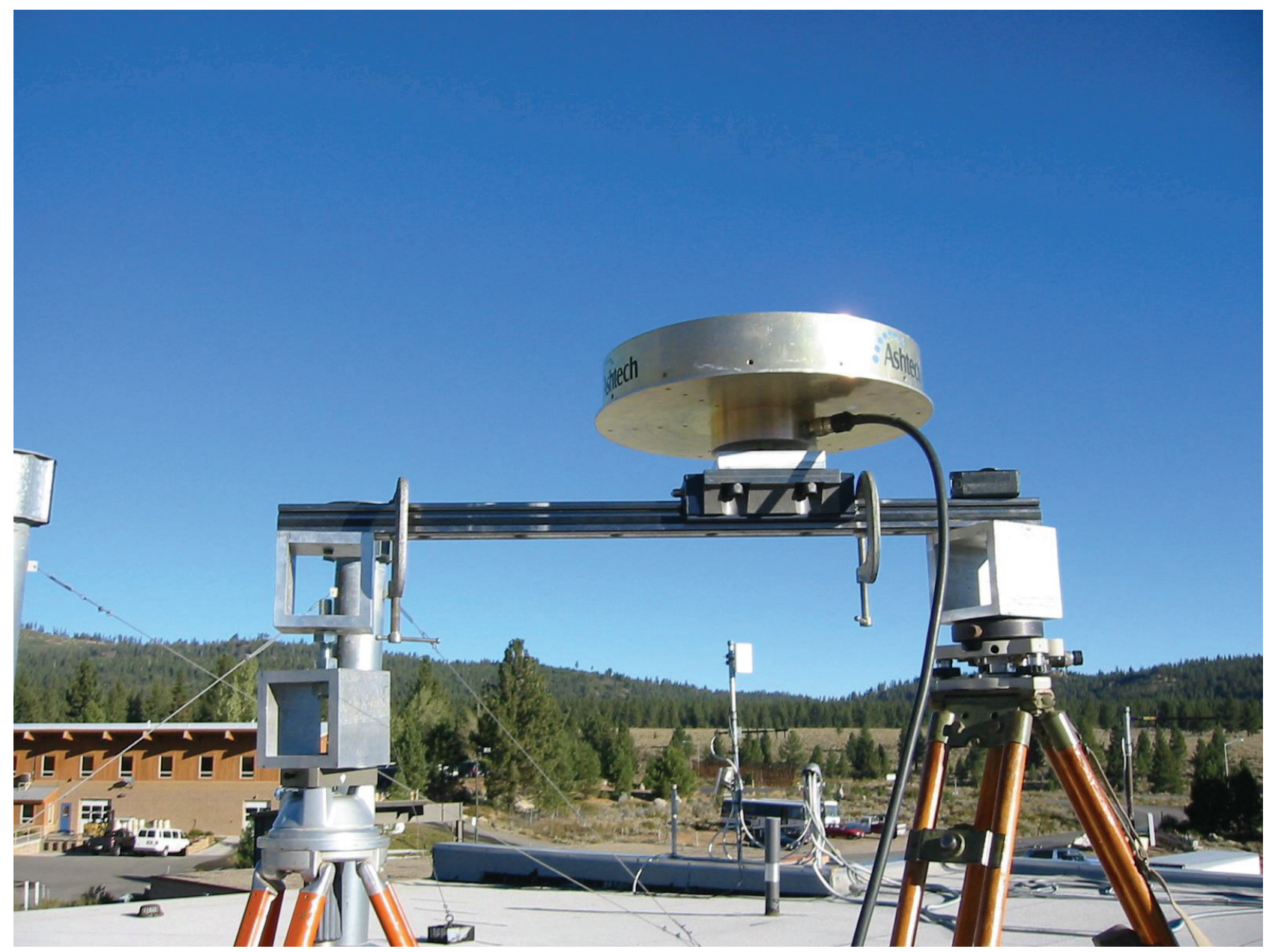

Figure 2; $\quad$ Experimental set up; more details of the slider and track

Figures 1 and 2 show more detail of the setup. By hand, the slider is pushed along the rail from one C-clamp to the second which acts as a stop. Since the slider has ball bearings, the translation can be done usually within 1 second.

The normal protocol for the experiment requires setting up the tripods and rail such that the rail is oriented approximately $\mathrm{N} 45^{\circ} \mathrm{E}$ and that the rail (or track) is level. The leveling is accomplished using the two cubic blocks on the left that are separated with a 5/8 inch by 11 threaded stock. A simple 'bulls-eye' level or carpenter's level placed temporally on the rail allows adjustment of the vertical position between the two cubes until the rail becomes level. The GPS antenna is fastened to the slider and the slider is set against one of the two C-clamps. A new antenna cable is hooked between the test antenna and the GPS receiver. The cable from the original antenna on site is disconnected from the receiver and the cable from the new set-up is connected. Once the new position test has stabilized as determined by the software, then the test antenna is translated to a new position against the second C-clamp. That displacement is independently measured with a tape measure. Several more translations are done over the course of the experiment with translation ranges between 1.5 and $35 \mathrm{~cm}$. Finally, the test antenna is disconnected and the original antenna was reconnected. For Long Valley, the total experiment consisted of 5 
translations over 48 hours and for Parkfield, the experiment consisted of 16 translations over 50 minutes.

For the RTD software at Parkfield, one parameter in the software needed to be changed. Since the test antenna was located about 25 meters from the antenna used for monitoring at Carh, the constraint on the position was changed from 1 to 100 meters.

Since the experiments at Parkfield and Long Valley took place at the site where the software resided, I was able to observe the offsets on the computer monitor during the course of the experiment.

\section{RTD at Parkfield}

Figure 3 shows the measured displacement by the RTD software after the test antenna was hooked up to the GPS receiver. The baseline length is $5.6 \mathrm{KM}$. In the discussion that follows, I will provide 3 numbers to describe the translation. The first number is the value measured by the tape measure on the test track. Nominally, the test track is oriented $\mathrm{N} 45^{\circ} \mathrm{E}$ and remains fixed throughout the experiment. The second and third numbers are the north and east displacements deduced from the GPS measurements.
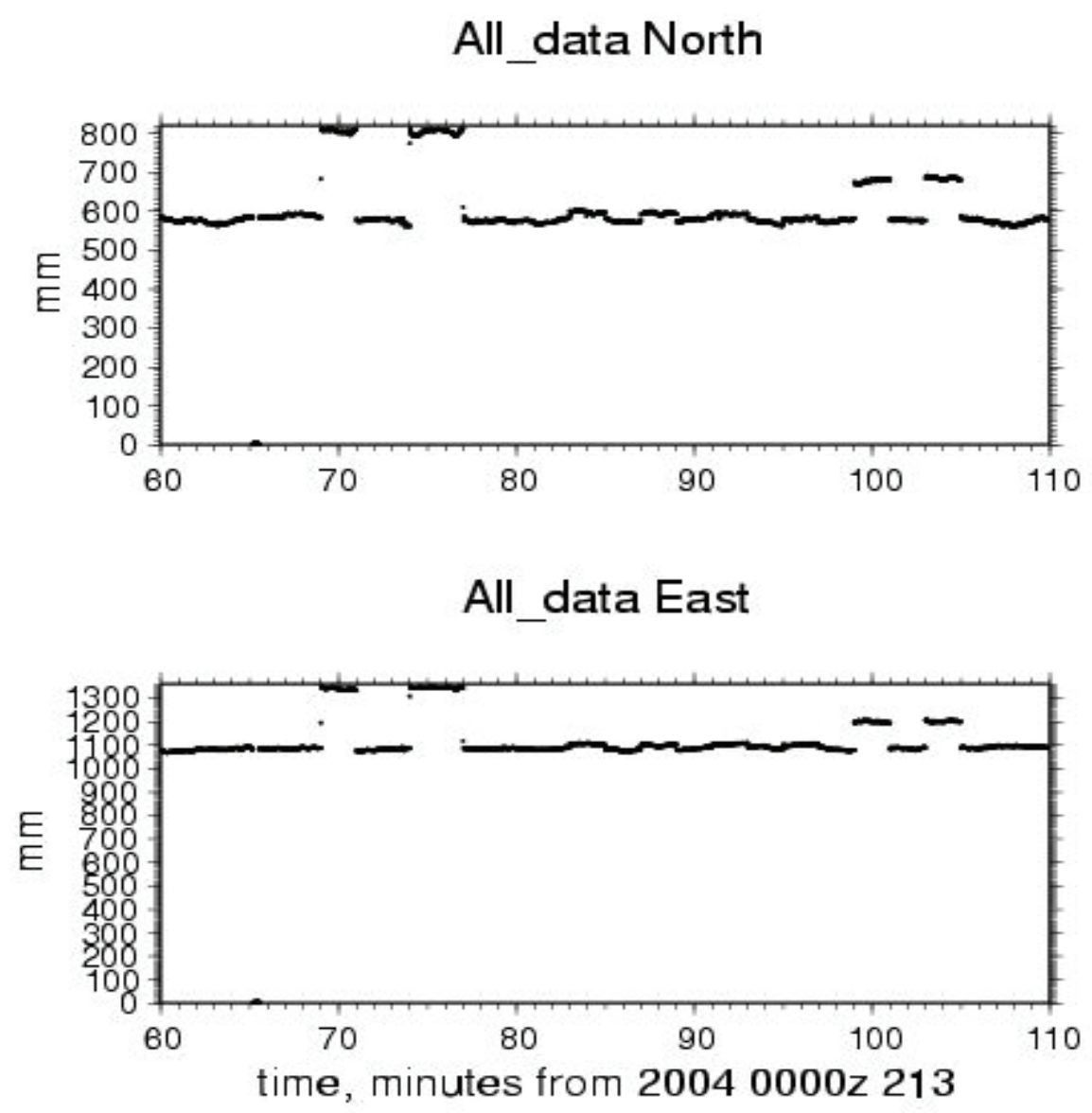

Figure 3; $\quad$ All of the translations at Parkfield 
Displacements were introduced at $69,71,74,77,83,85,87,89,91,93,95,97,99,101$, 103, and 105 minutes after 0000 hours GMT on day 213 of 2004. Only displacements greater than $30 \mathrm{~mm}$ are readily apparent at this scale. Surprisingly, there is an offset seen at about 65 minutes; this should be considered as an outlier since nothing was moved during the first 9 minutes of the experiment. I suspect that this outlier is due to the fact that the position constraint was loosened from 1 meter to 100 meters needed to run this experiment. The test antenna was setup about 25 meters from the antenna used for monitoring. Consequently, with the loser constraint, the tropospheric correction could trade-off with the estimate of the position.

Figure 4 show a blow-up of the results of moving the antenna approximately $350 \mathrm{~mm}$ $\mathrm{N} 45^{\circ} \mathrm{E}$ and back twice from 69 minutes to 77 minutes after 0000 GMT. Because I moved the antenna manually, one can see intermediate points during 3 of the 4 translations.

Figure 5 show two sets of translations each repeated twice. The first set is a pair of $26 \mathrm{~mm}$ translations at $83,85,87$, and 89 minutes after 0000GMT. The second set is a pair of $16 \mathrm{~mm}$ translations at 91, 93, 95, and $97 \mathrm{~min}$ after 0000. Although the data between the translations have considerable drift, the offsets are well resolved. However, there are apparent outliers at the $10 \mathrm{~mm}$ level. Figure 6 shows the results from the last set of translations.
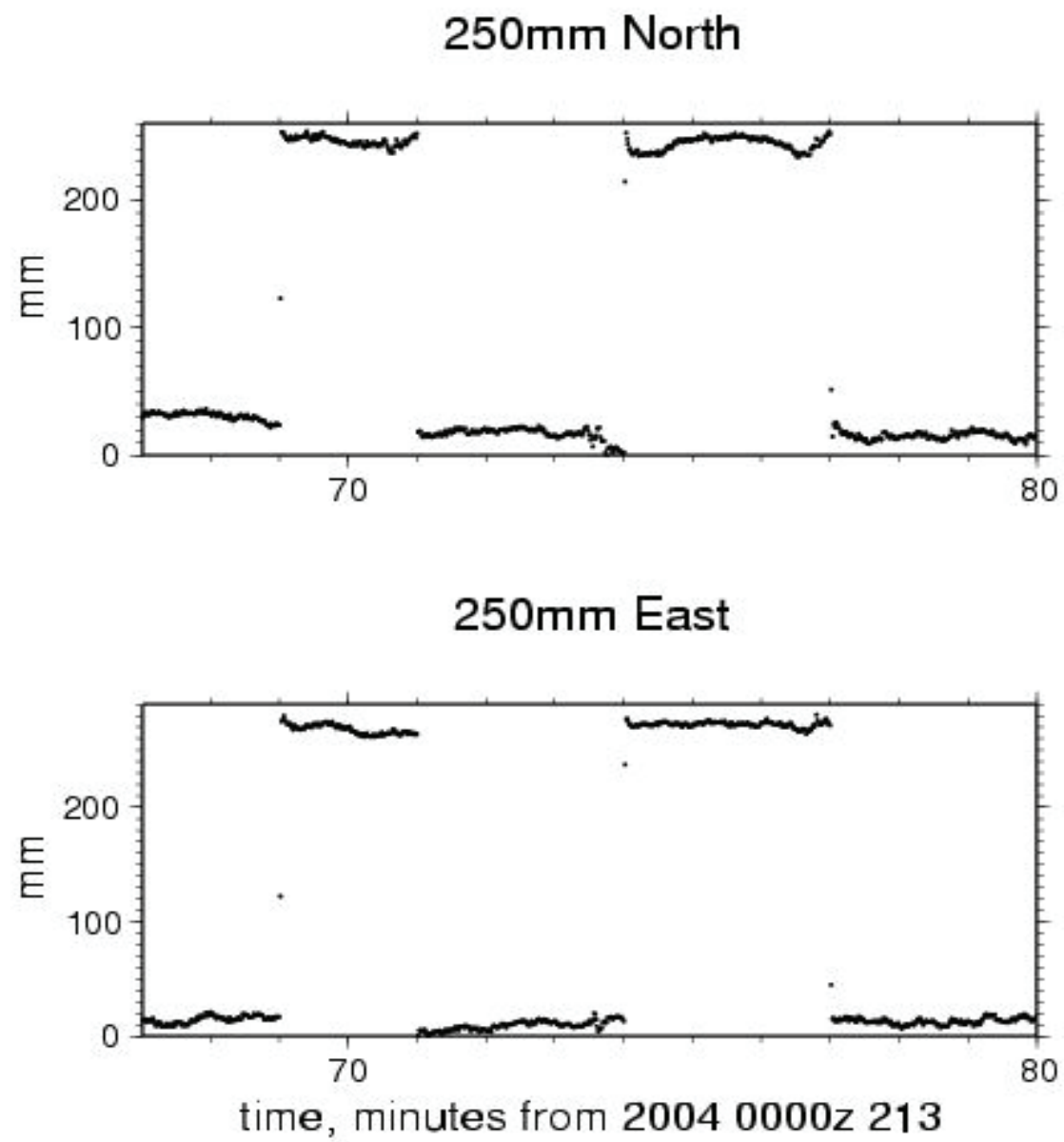

Figure 4; Details of initial translations 


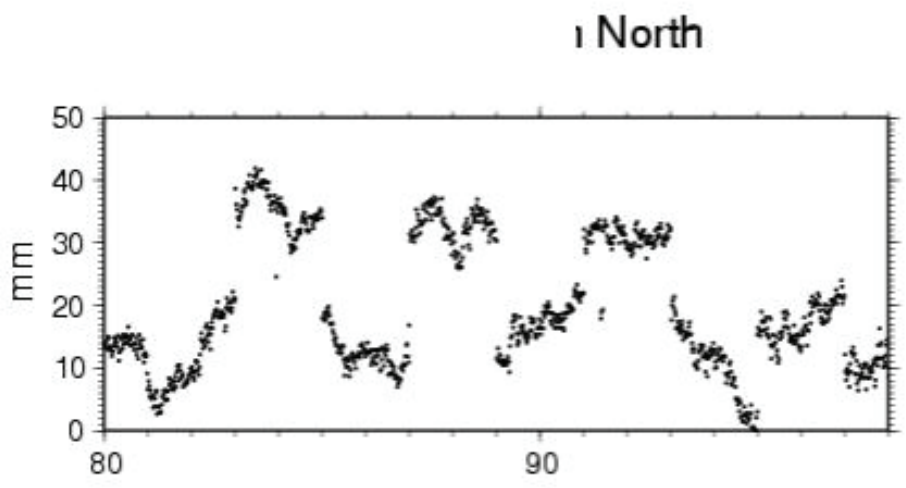

\section{East}

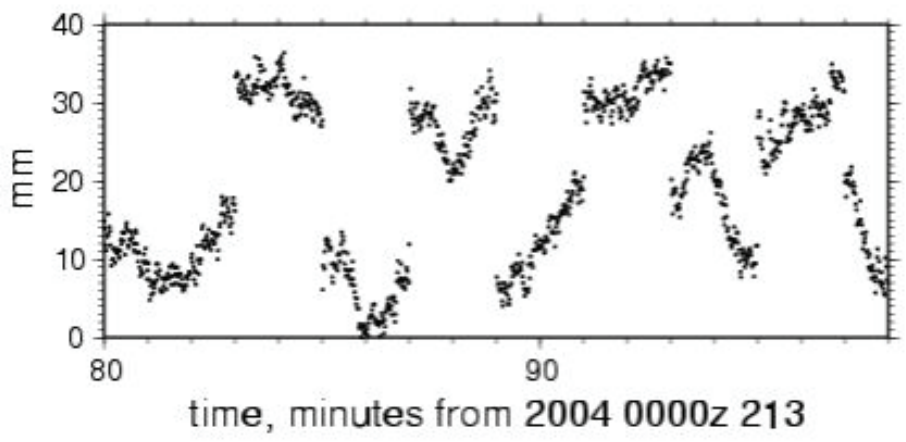

Figure 5; details of the smaller translations

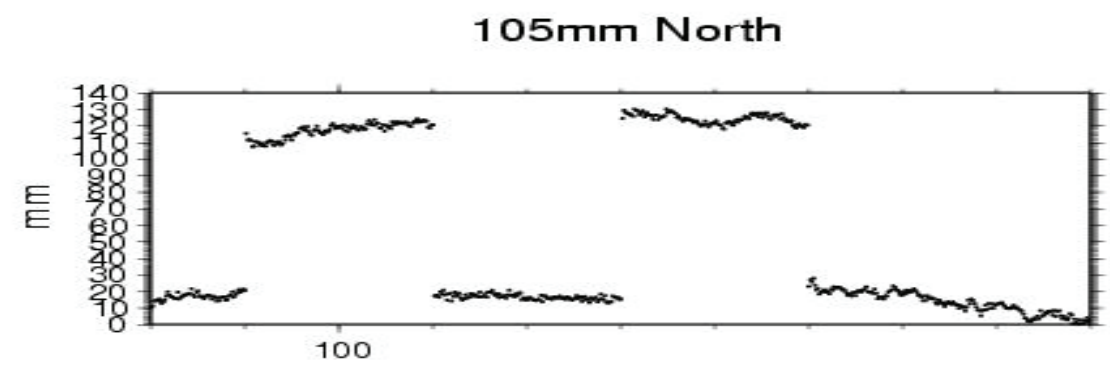

$105 \mathrm{~mm}$ East

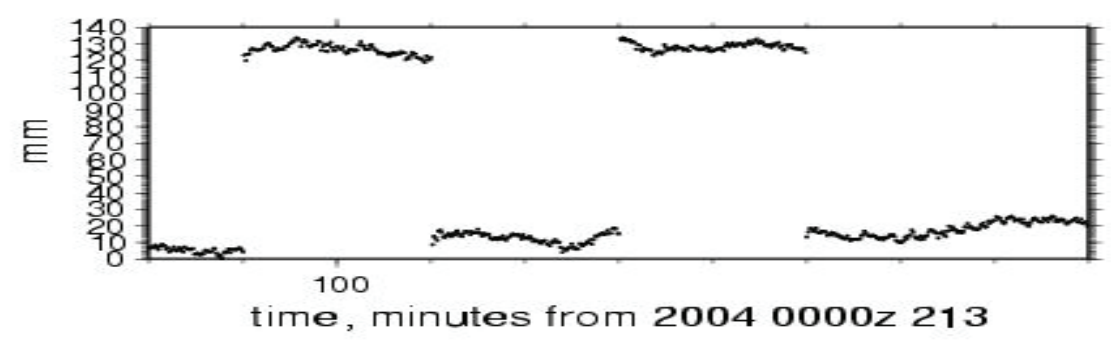


Figure 6; detail of the last set of translations

Using the data that span the 24 hour period of day 213 , I can formally estimate the offsets artificially introduced in the data using the method of Langbein (2004) to simultaneously estimate the offsets and the background noise model of the data. For computational savings, I decimated the data from 1 second to 5 second samples and used 3 hours of data that spanned the experiment. With this set of data, I could obtain both the sizes of the offsets and an estimate of the noise in the observations. One critical assumption is that the time of the offset is known; in many situations, the time of the offset is not known and needs to be evaluated using the displacement data and other data if available.

Table 1. Experimental offsets

\begin{tabular}{|l|l|l|l|l|}
\hline \multicolumn{1}{|c|}{ Time (minutes) } & \multicolumn{1}{|c|}{$\boldsymbol{E a s t}(\mathbf{m m})$} & \multicolumn{1}{c|}{ North $(\mathbf{m m})$} & \multicolumn{1}{c|}{ Magnitude } & \multicolumn{1}{c|}{ Measured (tape) } \\
\hline 69 & $260.1 \pm 1.8$ & $224.1 \pm 2.0$ & $343.3 \pm 1.9$ & 348 \\
\hline 71 & $-259.7 \pm 1.8$ & $-231.9 \pm 2.0$ & $348.2 \pm 1.9$ & 348 \\
\hline 74 & $259.4 \pm 1.8$ & $232.7 \pm 2.0$ & $348.5 \pm 1.9$ & 348 \\
\hline 77 & $-258.0 \pm 2.1$ & $-227.6 \pm 2.3$ & $344.0 \pm 2.9$ & 348 \\
\hline 83 & $18.5 \pm 1.8$ & $18.9 \pm 2.0$ & $26.4 \pm 1.9$ & 26 \\
\hline 85 & $-21.9 \pm 1.8$ & $-17.7 \pm 2.0$ & $28.2 \pm 1.9$ & 26 \\
\hline 87 & $21.1 \pm 1.8$ & $19.7 \pm 2.0$ & $28.9 \pm 1.9$ & 26 \\
\hline 89 & $-20.5 \pm 1.8$ & $-19.7 \pm 2.0$ & $28.4 \pm 1.9$ & 26 \\
\hline 91 & $12.8 \pm 1.8$ & $10.7 \pm 2.0$ & $16.7 \pm 1.9$ & 16 \\
\hline 93 & $-14.2 \pm 1.8$ & $-15.2 \pm 2.0$ & $20.8 \pm 1.9$ & 16 \\
\hline 95 & $15.9 \pm 1.8$ & $14.1 \pm 2.0$ & $21.3 \pm 1.9$ & 16 \\
\hline 97 & $-13.8 \pm 1.8$ & $-11.6 \pm 2.0$ & $18.0 \pm 1.9$ & 16 \\
\hline 99 & $118.7 \pm 1.8$ & $95.3 \pm 2.0$ & $152.2 \pm 1.9$ & 150 \\
\hline 101 & $-109.5 \pm 1.8$ & $-103.9 \pm 2.0$ & $150.9 \pm 1.9$ & 150 \\
\hline 103 & $115.0 \pm 1.8$ & $109.1 \pm 2.0$ & $158.6 \pm 1.9$ & 150 \\
\hline 105 & $-110.8 \pm 1.8$ & $-98.0 \pm 2.0$ & $147.9 \pm 1.9$ & 150 \\
\hline
\end{tabular}

The values of the estimated offsets estimated by RTD are close to those measured by a tape measure. The hand measurements have a precision of about $2 \mathrm{~mm}$.

Table 2. Noise models of the data

\begin{tabular}{|l|l|l|}
\hline & \multicolumn{1}{|c|}{ East } & \multicolumn{1}{c|}{ North } \\
\hline White noise $(\mathrm{mm})$ & 0.8 & 1.0 \\
\hline Power law index $(\mathrm{n})$ & 1.51 & 1.43 \\
\hline Power law amplitude $\mathrm{mm} / \mathrm{yr}^{\mathrm{n} / 4}$ & 634 & 534 \\
\hline
\end{tabular}


The noise amplitudes are close to those obtained by Langbein and Bock (2004).

\section{DTracker Long Valley-Experiment 1, September 2004}

Figures 7 and 8 show the displacements estimated by 3DTracker over the 3 day span of the experiment. The solution is based on the "Iono-free Carrier and Iono-free Code" solution of 3DTracker. The baseline length is $16.3 \mathrm{KM}$ (Bald to Mwtp).
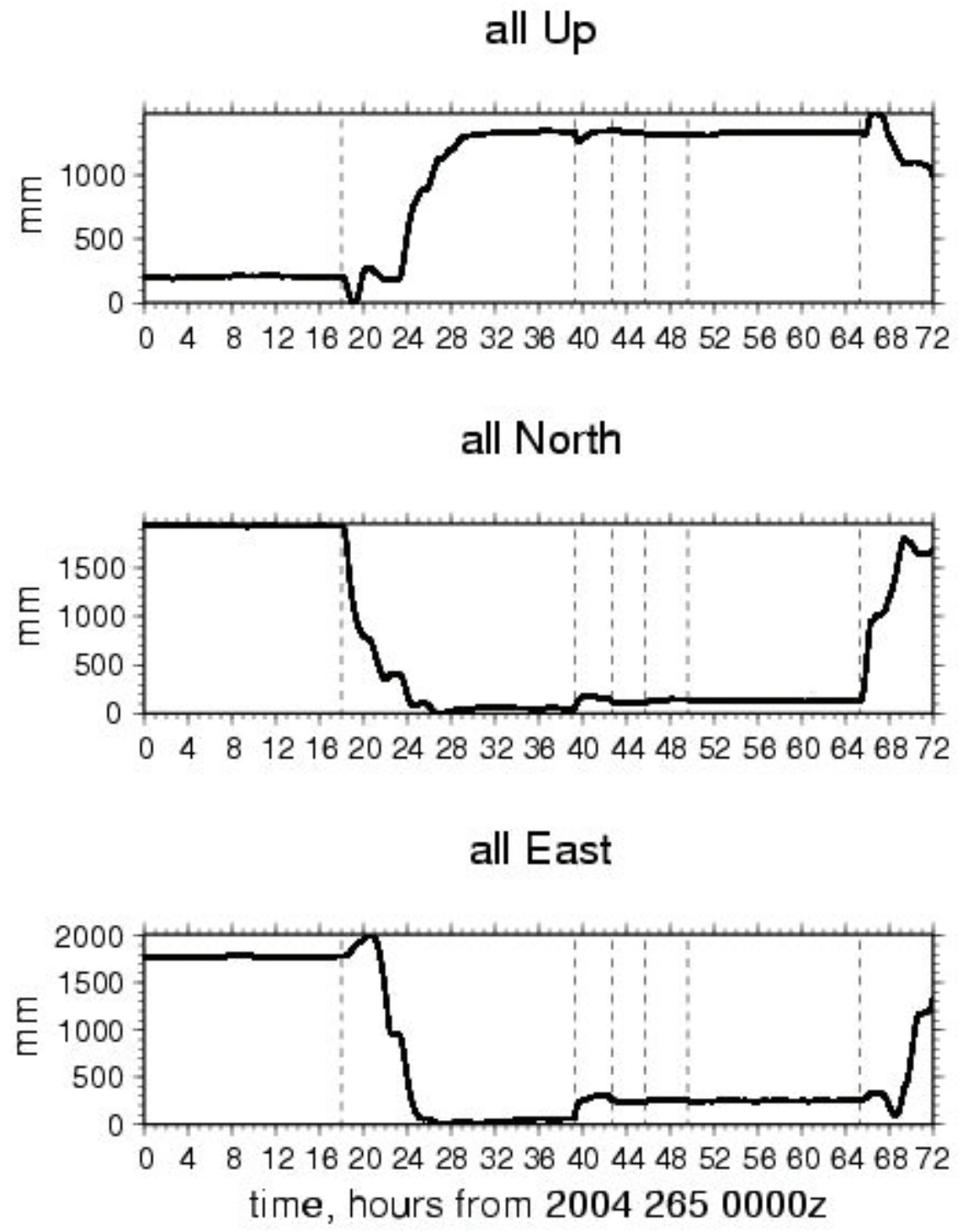

Figure 7; Initial set-up and all of the translations 


\section{translations Up}

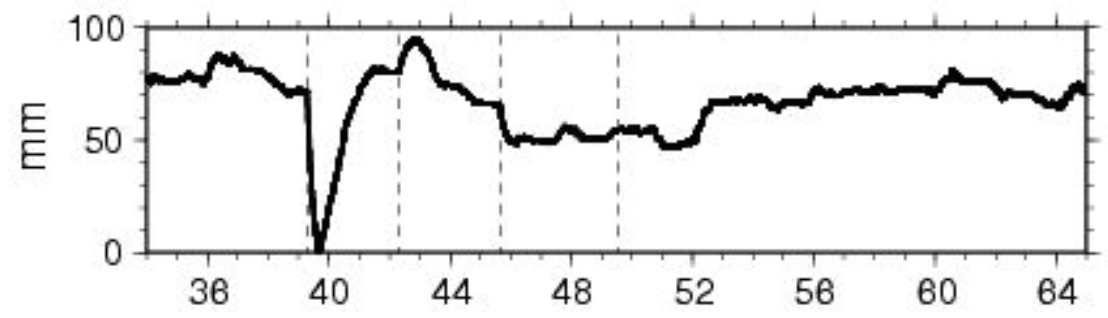

translations North

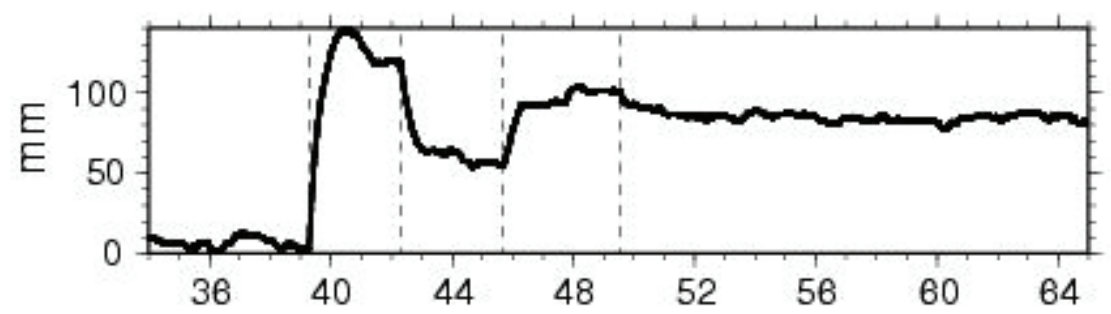

translations East

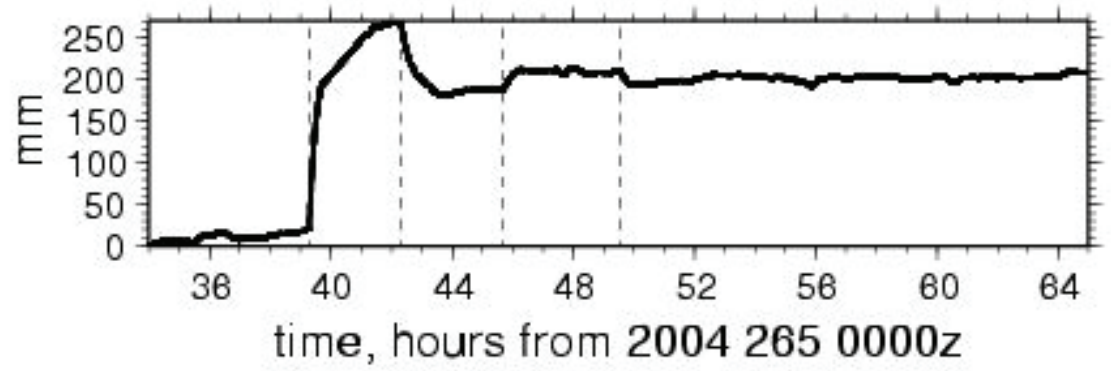

Figure 8; $\quad$ All four translations

At 18 hours on day 265, I switched the antenna to the test antenna located approximately 2.5 meters from the monitoring antenna (shown in Figure 1). The data show in in Figure 7 indicates that it took approximately 10 hours for the solution to stabilize. The gain of the Kalman filter was set to $1 \times 10^{-7}$ which controls the temporal variation or data smoothing. At 65 hours, the antenna was changed back to the original antenna used for monitoring. The dashed vertical lines show the times of these changes and the times of the translations.

Once the antenna was shifted to the test set-up, I allowed about 22 hours for the solutions to stabilize. Over the course of the next 10 hours, I translated the antenna 4 times, first $300 \mathrm{~mm} \mathrm{NE}$ at 39.28 hours, $150 \mathrm{~mm} \mathrm{SW}$ at 42.30 hours, $75 \mathrm{~mm} \mathrm{NE}$ at 45.65 hours, and $28 \mathrm{~mm}$ to the $\mathrm{SW}$ at 49.57 hours. Figure 9 shows a magnified plot of the results from smaller translations with better resolution than figure 8 . In the 4 translation experiments, the data suggest that there was a vertical 
translation, too (figure 8 and 9). However, the track of the slider was adjusted to be level and, to within a millimeter, there should be no vertical motions.

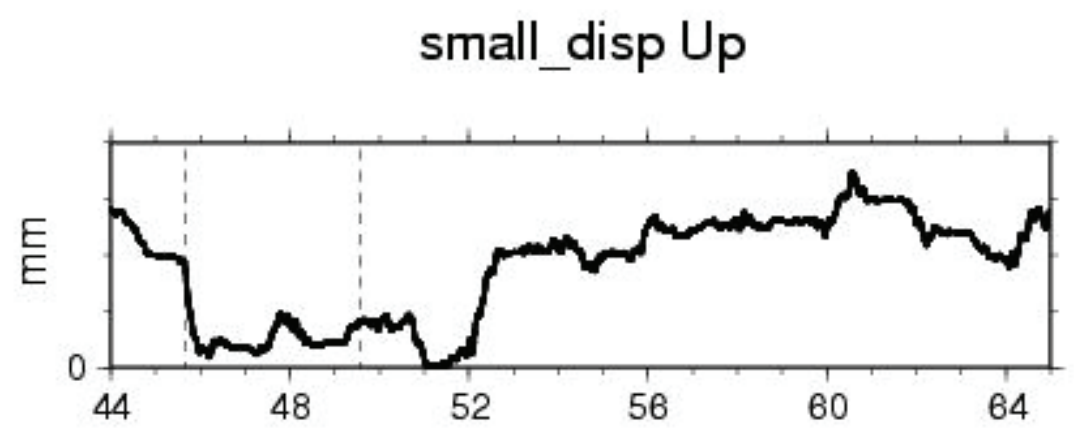

\section{small_disp North}

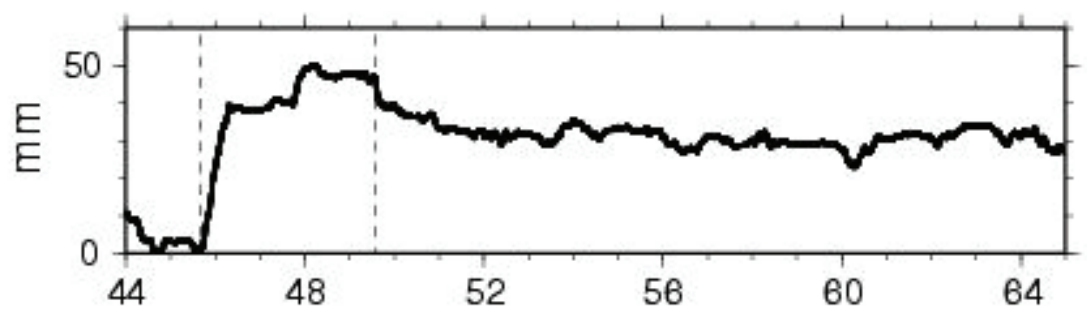

small_disp East

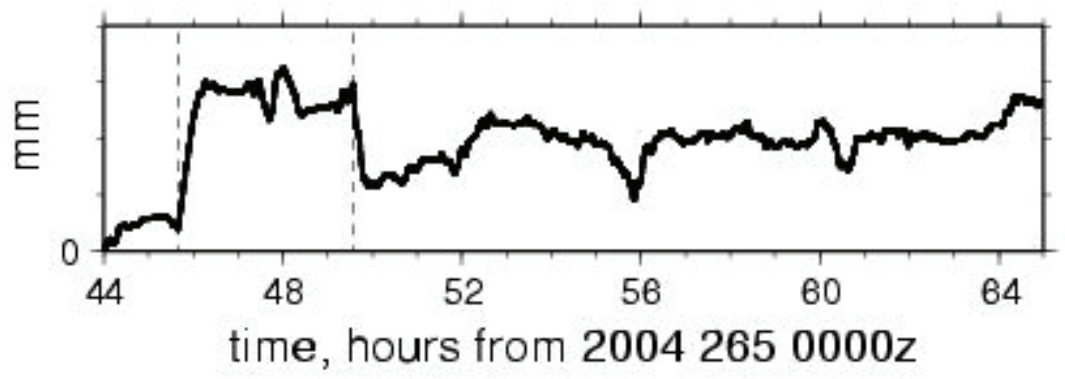

Figure $9 ; \quad$ Small translations

According to the literature distributed with 3DTracker, the Kalman gain, Q, limits the velocity that the software can track. For a value of $\mathrm{Q}=10^{-7}$ (meters/sample epoch) ${ }^{2}$ and a sampling interval of 5 seconds, a displacement will be limited to a velocity of $0.06 \mathrm{~mm} / \mathrm{sec}$, or $4 \mathrm{~mm} / \mathrm{min}$, or $0.23 \mathrm{~m} /$ hour. This suggests for "fast" translations ( $>10 \mathrm{~mm} / \mathrm{sec}$ ) that I made would been seen as a slower movement. Indeed, this is the case. However, visual inspection of the data indicates the apparent velocities ranged from $0.04 \mathrm{~m} / \mathrm{hr}$ to $0.25 \mathrm{~m} / \mathrm{hr}$ and is proportional to the amount of translation. That is, for the initial antenna change of about 2.5 meters (or 1.8 meters for east and 
north), it took about 7 hours or $0.25 \mathrm{~m} / \mathrm{hr}$. However, for the smaller translations, the software required about 1 hour and averaged about $0.05 \mathrm{~m} / \mathrm{hr}$.

Finally, the table below summarizes the magnitude of the estimated displacement with the actual displacements.

Table 3. S Statistics from translation experiments at Long Valley, September 2004.

\begin{tabular}{|l|l|l|l|}
\hline \multicolumn{1}{|c|}{ Time, hours } & \multicolumn{1}{|c|}{$\begin{array}{c}\text { Estimated horizontal } \\
\text { displacement,mm }\end{array}$} & $\begin{array}{c}\text { Measured displacement (tape } \\
\text { measure }), \text { mm }\end{array}$ & $\begin{array}{c}\text { Estimated } \\
\text { translation rate } \\
(\boldsymbol{m} / \mathbf{h r})\end{array}$ \\
\hline 18 & 2520 & Not precisely measured & 0.25 \\
\hline 39.28 & 272 & 300 & 0.09 \\
\hline 42.3 & 89 & 150 & 0.09 \\
\hline 45.65 & 44 & 75 & 0.05 \\
\hline 49.5 & 16 & 28 & 0.05 \\
\hline
\end{tabular}

Except for the initial set-up, the result of the 4 translation experiments suggest that the software takes longer than advertised to stabilize. Each displacement estimated above tended to be less than the actual translation of the antenna. Additional time may have been required to allow the solution to stabilize to the correct value of offset. However, that would imply even a longer settling time than predicted by Q.

\section{Long Valley Experiment 2, September 2005.}

This experiment is a repeat of the first experiment described above using 3DTracker. However, two baselines were measured instead of one; Bald-Mwtp (16.3 KM) and Tilc-Mwtp (7.7 $\mathrm{KM})$. In addition, the 5 second sampled pseudo-range data was saved as RINEX files for later analysis using various software packages including other processing options in 3DTracker. Unfortunately, the pseudo-range data from the first experiment were not saved, thus the motivation to repeat the experiment at Long Valley. With the 2005 experiment, an upgraded version, (Number 1.3.06) of 3DTracker was used. 


\section{BALD to MWTP \\ north A 05}
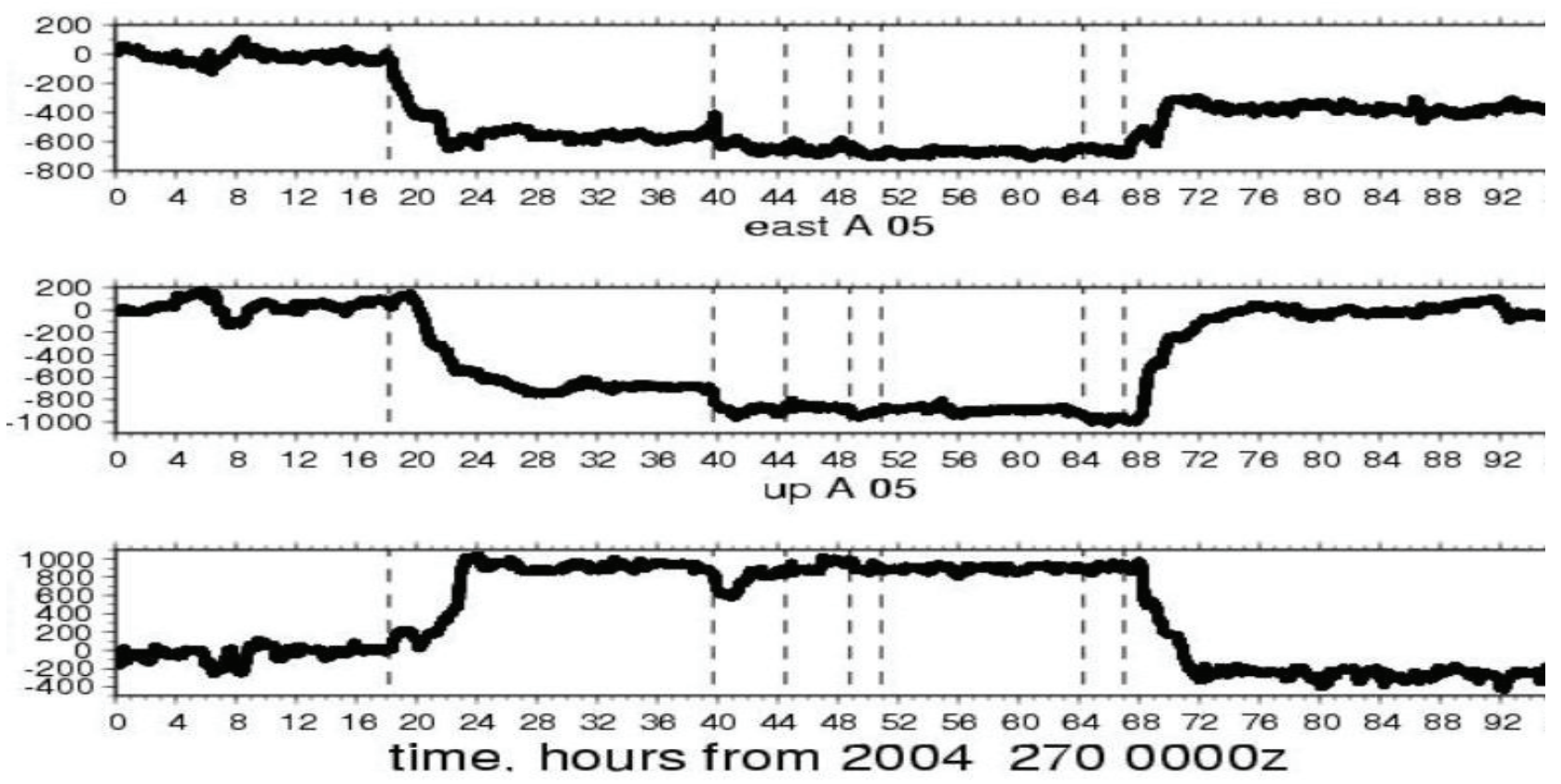

Figure 10: $\quad$ Displacement test to Bald; 3 Dtracker; $0=10^{\wedge}-5$; original results

\section{TILC to MWTP}

north A 05
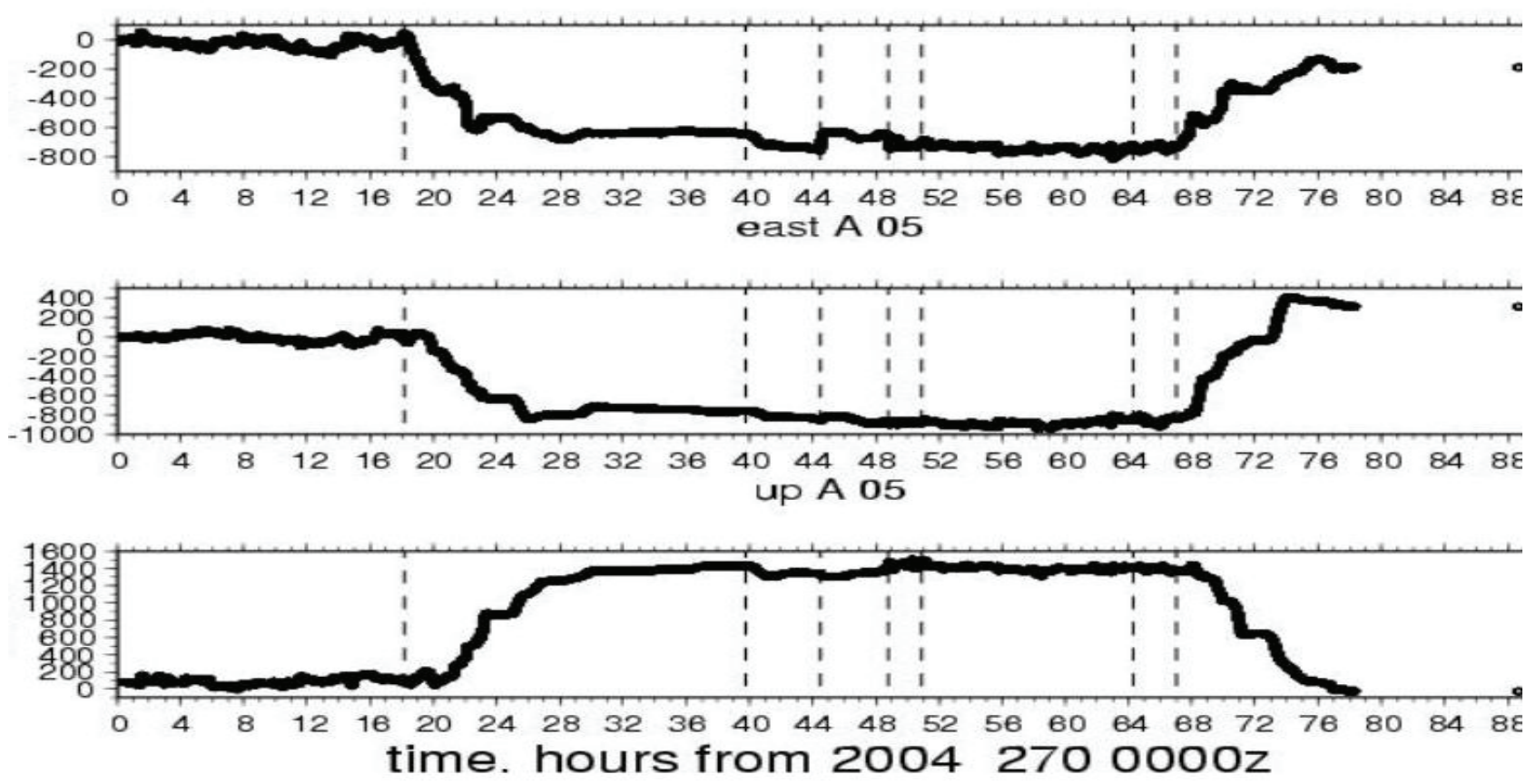
Figure 11: Displacement test to Tilc; $3 D$ Tracker; $0=10^{\wedge}-05$; Original results

Figures 10 and 11 show the position changes of Mwtp relative to Bald (Figure 10) and Tilc (Figure 11) as estimated by 3DTracker in real-time. The dashed lines at 18 hour sand 67 hours are the antenna swaps; the dashed lines near 40, 44, 49, 51 and 64 hours are translations of the antenna on the test jig. The Kalman gain was set to $10^{-5}$. 3DTracker has several options $(>10)$ with respect to the "observable" data channels; for this experiment, the "Iono-free Carrier and Iono-free Code" data was chosen because I thought this might yield the best result.

\section{BALD to MWTP}

\section{north A 05}
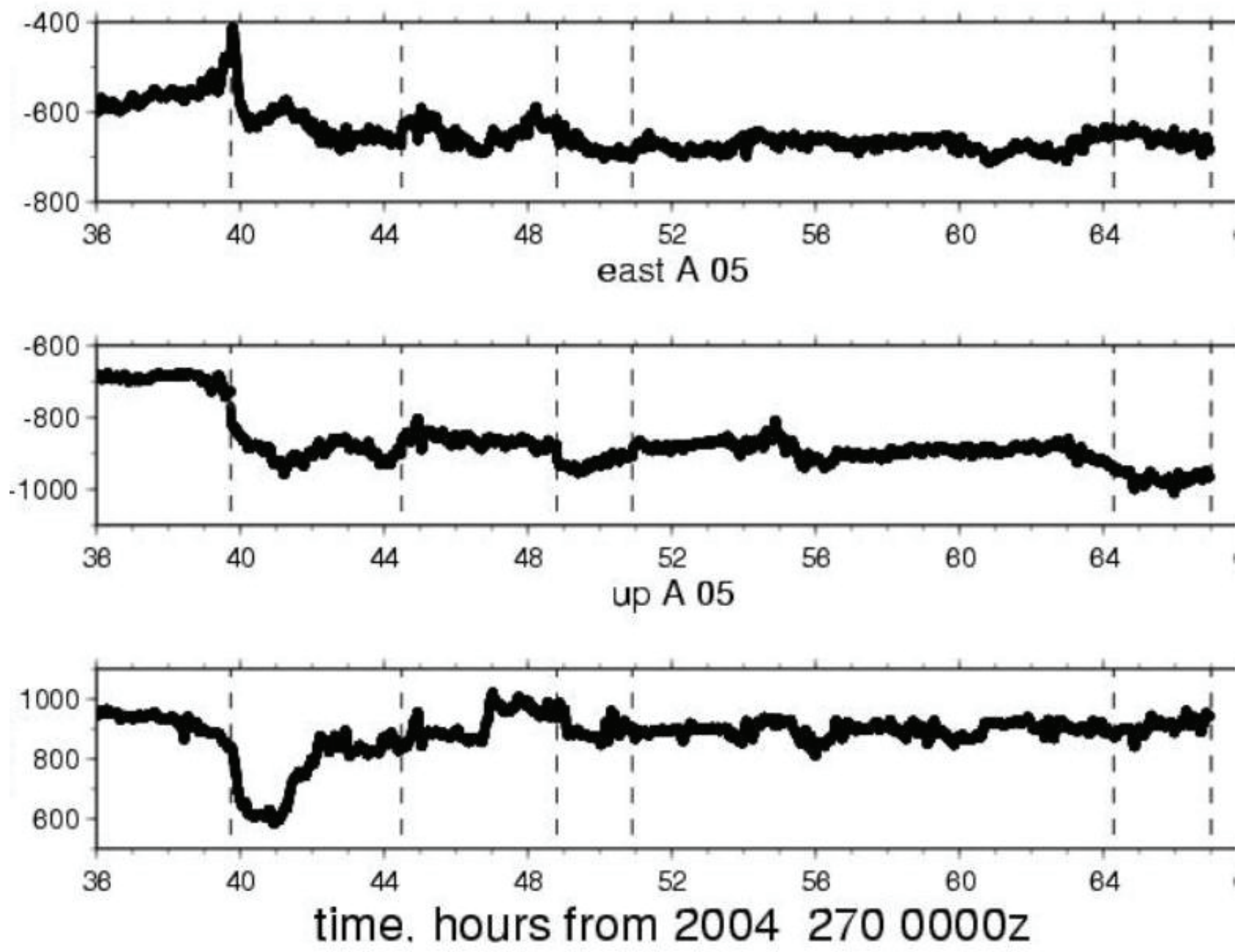

Figure 12; Displacement test to Bald; $3 \mathrm{DTracker} ; \mathrm{Q}=10^{\wedge}-5$; Original results for translations 


\section{TILC to MWTP}

north A 05
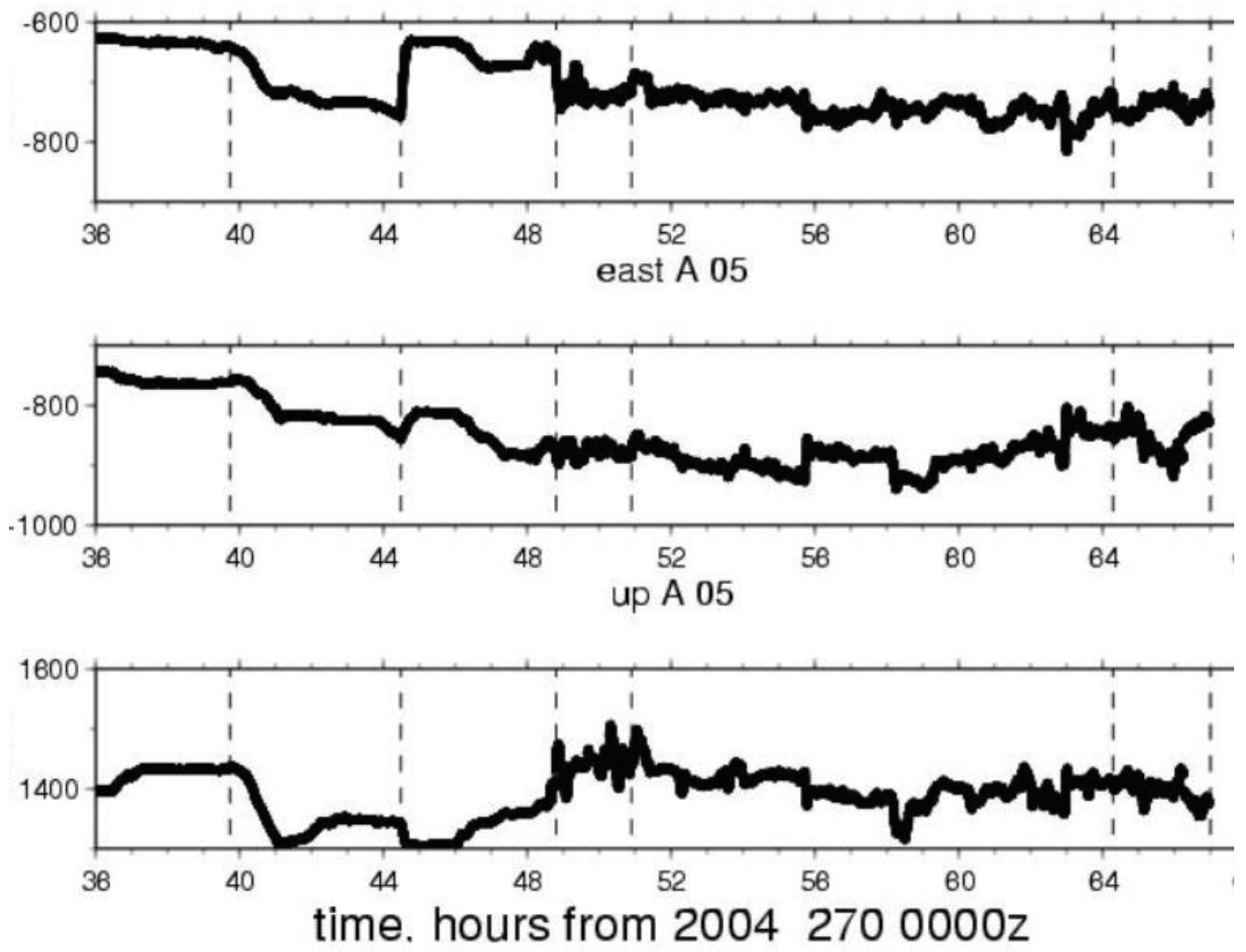

Figure 13: Displacement test to Tilc; $3 D$ Tracker; $0=10^{\wedge}-5$; Original results for translations

Figures 12 and 13 show the results of the 5 translations oriented approximately $\mathrm{N} 45^{\circ} \mathrm{E}$ carried out during the experiment. The horizontal translations are: $280 \mathrm{~mm}(\mathrm{SW}), 141 \mathrm{~mm}(\mathrm{NE})$, $71 \mathrm{~mm}(\mathrm{SW}),+33 \mathrm{~mm}(\mathrm{NE})$, and $-16 \mathrm{~mm}(\mathrm{SW})$. Within a millimeter, there are no vertical translations. Examination of the real-time results in Figures 12 and 13 indicate that the translations are poorly resolved; even though there were no vertical translations, the estimates of the vertical position shows a transient between 40 and 42 hours. In addition, for the two largest translations, the real-time plots suggest differing offsets.

After the experiment, the 5-second samples recorded at Mwtp, Bald, and Tilc were converted to RINEX files. I used these files to experiment with different settings in 3DTracker. Initially, I replayed the RINEX files through 3DTracker using the same settings as the experiment, a Kalman gain of $10^{-5}$, and, using the same settings as I did during the actual experiment, I got the 
results shown in Figures 14 and 15. For the Tilc baseline, comparing the results shown in Figure 15 with Figure 11 indicates a problem with those data for which I do not have an explanation. It would appear that the Kalman gain was set incorrectly to $10^{-7}$ (or less), but this is not the case. For the Bald baseline, the results in Figure 14 are similar to those obtained in real-time, Figure 10.

However, there is a difference in the north component near hour 69. This corresponds to the time when the antenna was swapped from the test jig back to its original configuration; the north component in Figure 10 indicates an incomplete reset; the reprocessed data in Figure 14 indicates a complete reset. One cause for the apparent difference is that, during the experiment, one can change the reference position by doing a "zero reset"; this allows the operator to keep the plot of position changes on scale on the computer monitor. It is possible that a reset command was executed but in re-examining the data, the size of the reset was lost.

\section{BALD to MWTP}

\section{north BAMWIF 05}
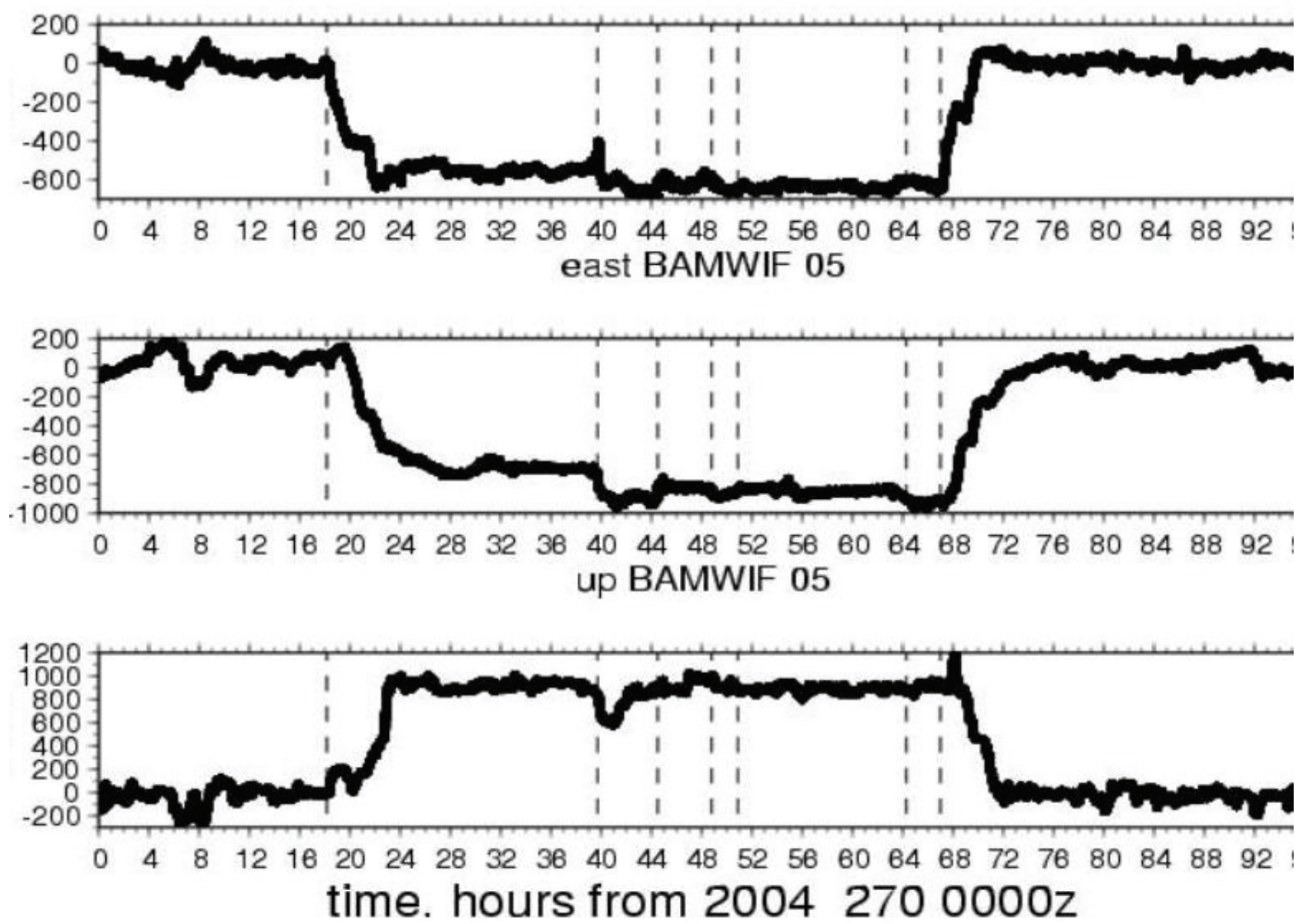

Figure 14: $\quad$ Replaying BALD data through 3DTracker; compare with Figure 10. 


\section{TILC to MWTP}

north TIMWIFC 05
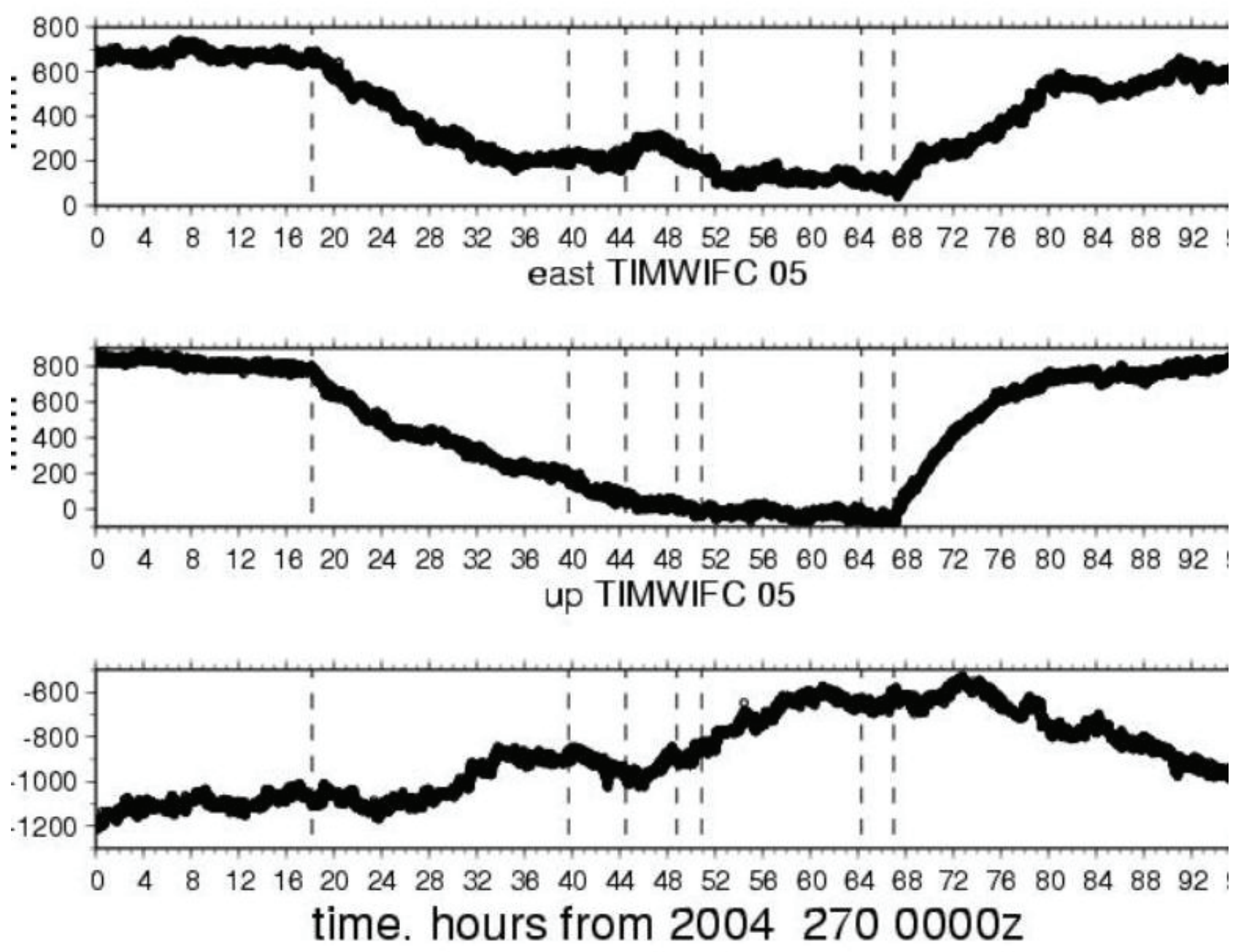

Figure 15; Replaying Tilc data through 3DTracker; Compare to Figure. 11

Given the problem encountered with the Tilc data, only the Bald data will be examined in more detail. In Figure 16, the Bald data was played back using the original, Ionosphere free observable, the L1 and L2 combination of observables, and only the L1 frequency. In all of these examples and the ones that follow, code data was used, too. Results of observing the measured translation between 36 and 68 hours suggests that the using the L1 frequency can detect the translation. The translation in the east component at 40 hours is well defined. However, the translation in the north appears to take 0.5 hours. Corresponding to that slow translation is an apparent motion in the vertical; that component should show no motion. 

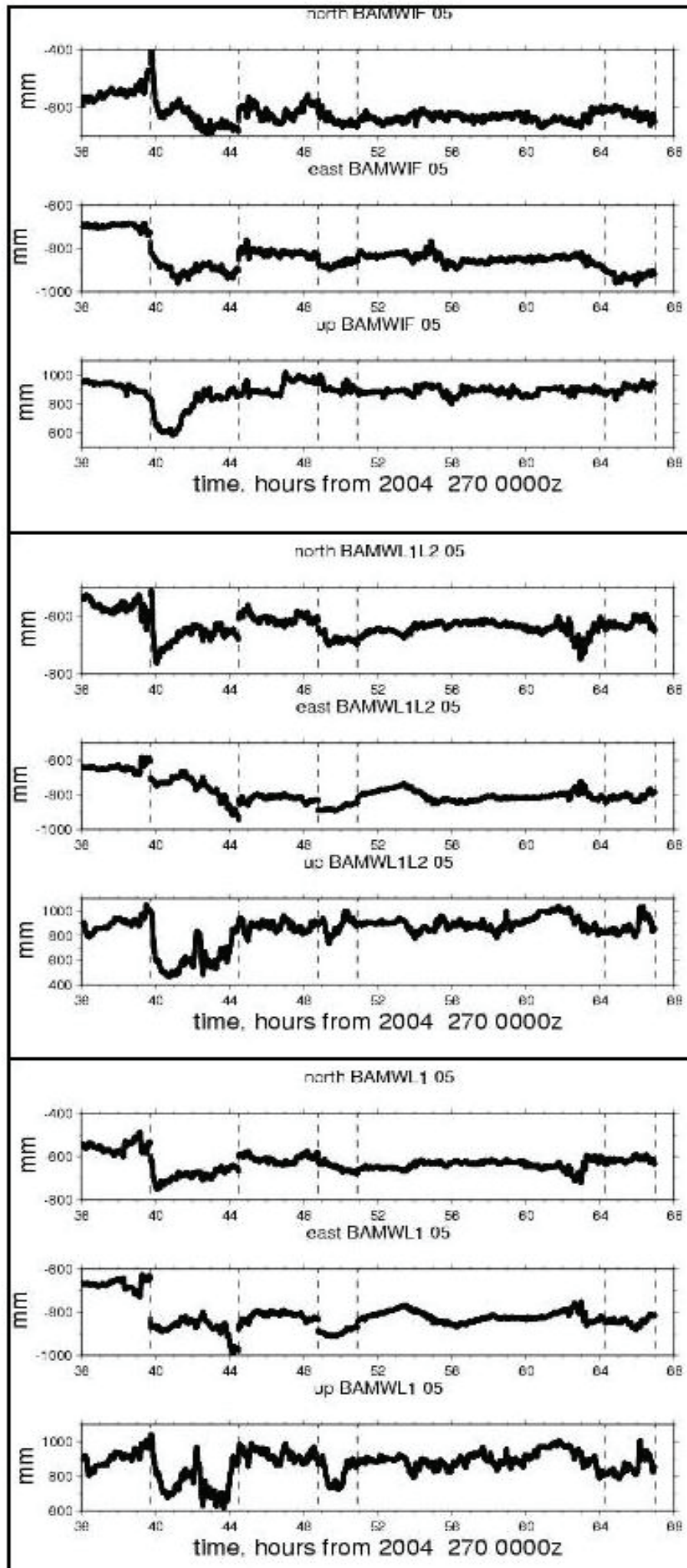

L1 and L2 Frequencies

L1 Frequency only

lonosphere Free 
Figure 16; Playback of Bald data using 3 different options in 3DTracker; Kalman gain was set to $10^{-5}$. results shown are for measured offsets.

Examination of solutions using only the L1 frequency but with varying Kalman gains indicates that gains of $10^{-3}$ and $10^{-5}$ can resolve the translations but, many other varying signals with similar magnitude as the translations are also seen. With a gain of $10^{-7}$, the translations lack the definitive, step response. Relative to the other two gains, the $10^{-7}$ gain has less noise (or more smoothing). 


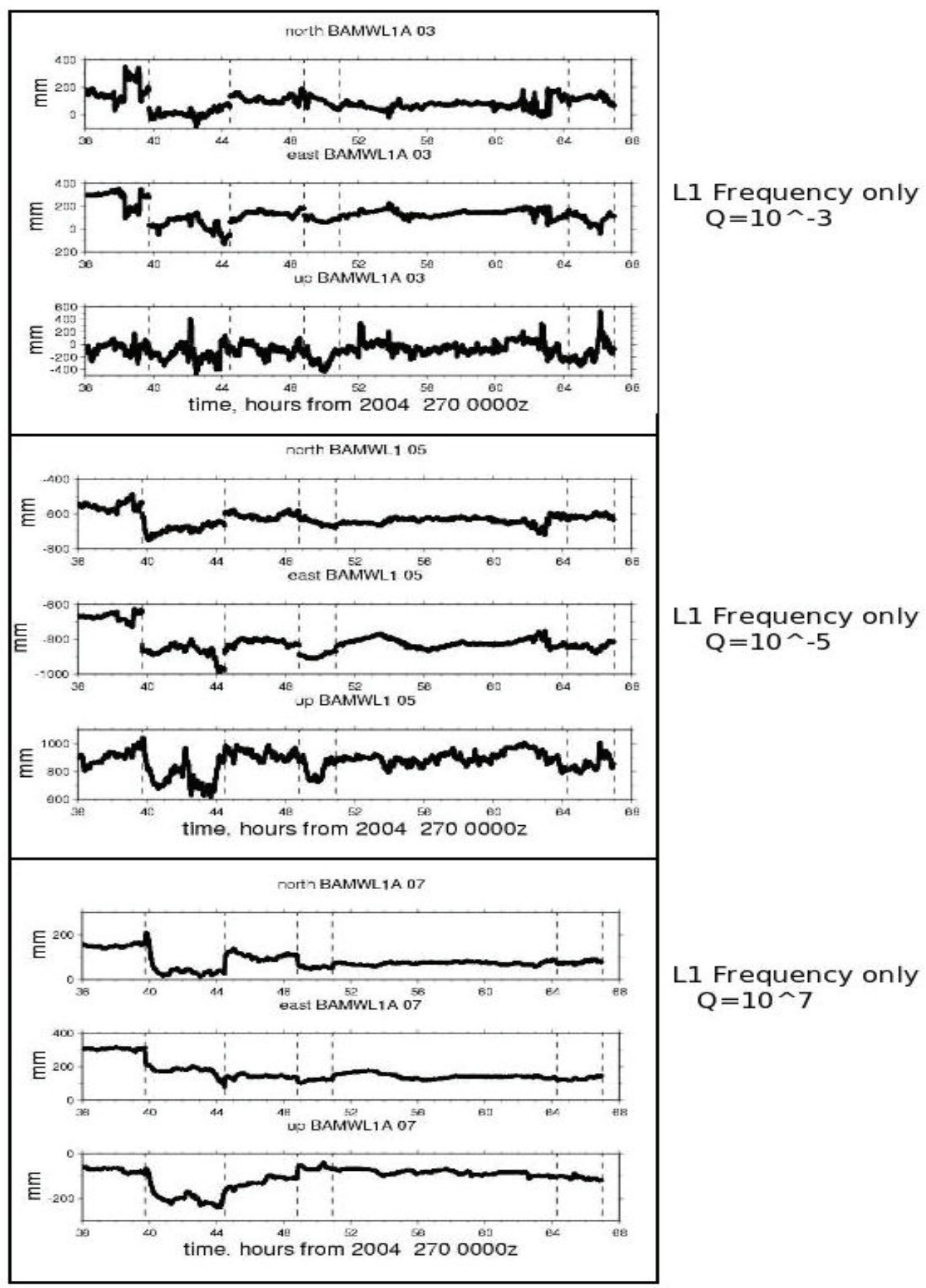

Figure 17: $\quad 3 D T r a c k e r$ results for Bald using only L1 frequency but with different Kalman gains (Q)

Using the same methods employed estimating the offset with the RTD experiment at Parkfield, the offsets are estimated using the 3DTracker L1 data with the Kalman gain set at $10^{-5}$ Table 4Experimental offsets 


\begin{tabular}{|l|l|l|l|l|}
\hline \multicolumn{1}{|c|}{ Time (hours) } & \multicolumn{1}{|c|}{ East $(\mathbf{m m})$} & \multicolumn{1}{|c|}{ North $(\mathbf{m m})$} & \multicolumn{1}{c|}{ Magnitude } & Measured (tape) \\
\hline 40 & $-213.2 \pm 2.4$ & $-77.1 \pm 2.8$ & $-226.5 \pm 2.4$ & -280 \\
\hline 44 & $111.9 \pm 2.4$ & $67.9 \pm 2.8$ & $130.9 \pm 2.5$ & 141 \\
\hline 46 & $-52.7 \pm 2.4$ & $-30.6 \pm 2.8$ & $-60.9 \pm 2.5$ & -71 \\
\hline 51 & $24.0 \pm 2.4$ & $16.8 \pm 2.8$ & $29.3 \pm 2.5$ & 33 \\
\hline 64 & $-13.7 \pm 2.4$ & $-10.2 \pm 2.8$ & $-17.1 \pm 2.5$ & -16 \\
\hline
\end{tabular}

Table $5 . \quad$ Noise models of the data

\begin{tabular}{|l|l|l|}
\hline & \multicolumn{1}{|c|}{ East } & \multicolumn{1}{c|}{ North } \\
\hline White noise $(\mathrm{mm})$ & $<0.3$ & $<0.3$ \\
\hline Power law index $(\mathrm{n})$ & 2.45 & 2.44 \\
\hline Power law amplitude $\mathrm{mm} / \mathrm{yr}^{\mathrm{n} / 4}$ & 7510 & 8580 \\
\hline Gauss Markov frequency, $\mathrm{rad} / \mathrm{yr}$ & 6510 & 4540 \\
\hline
\end{tabular}

With the exception of the $280 \mathrm{~mm}$ translation, the using L1 data and a Kalman gain of $10^{-5}$ 3DTracker appears to be able to estimate the size of the translations. However, there are several caveats apparent when examining the data shown in Figure 16 and 17. Often, the displacements appear to take several minutes to be tracked and, additional, spurious displacements are seen that exceed the $2.5 \mathrm{~mm}$ uncertainty. In the process of simultaneously estimating the offsets and the error model, the computer program had great difficulty in converging to a satisfactory result. This is very unusual and indicates that the noise model used may not be appropriate.

\section{Long Valley Experiment 2; Replaying the data using TRACK}

The RINEX files obtained from the September 2005 experiment were processed using TRACK. Initially, the 5 second data were decimated to 30 second sampling. The results of processing the Bald to Mwtp data are shown in Figure 18. The "default" settings were used initially. 


\section{MWTP to BALD}
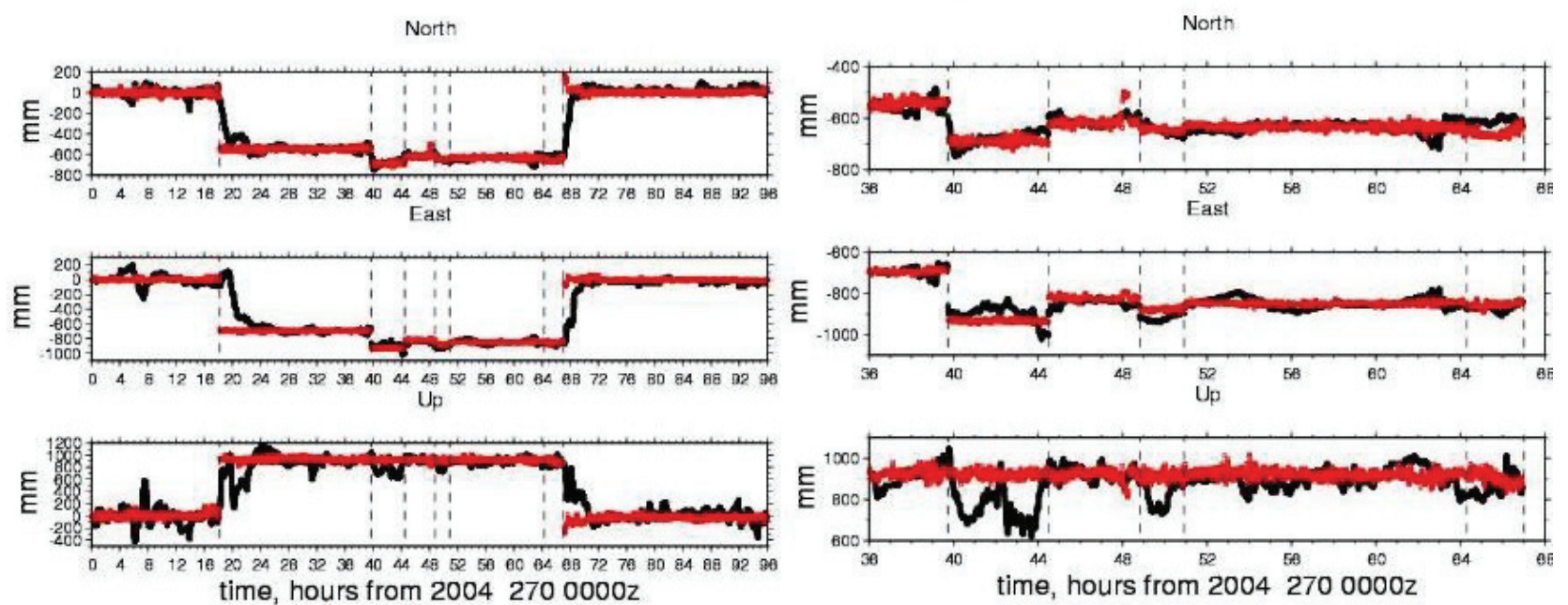

3DTracker, L1 and $\mathrm{Q}=10^{\wedge}-5$

\section{TRACK}

Figure 18: Comparison of displacement estimated by 3DTracker (black) and TRACK (red). Left hand side is data from the entire experiment. Right hand side is data from the measured translations.

By manually "fixing" the integer ambiguities of the solution, the data, shown in Figure 19, show that all, with the possible exception of the smallest translation, are well resolved using TRACK. By fixing ambiguities, all of the small offsets shown in Figure 18 that are not associated with the antenna swap or translations are eliminated and the results provide a very clean record of displacements. 


\section{MWTP to BALD}
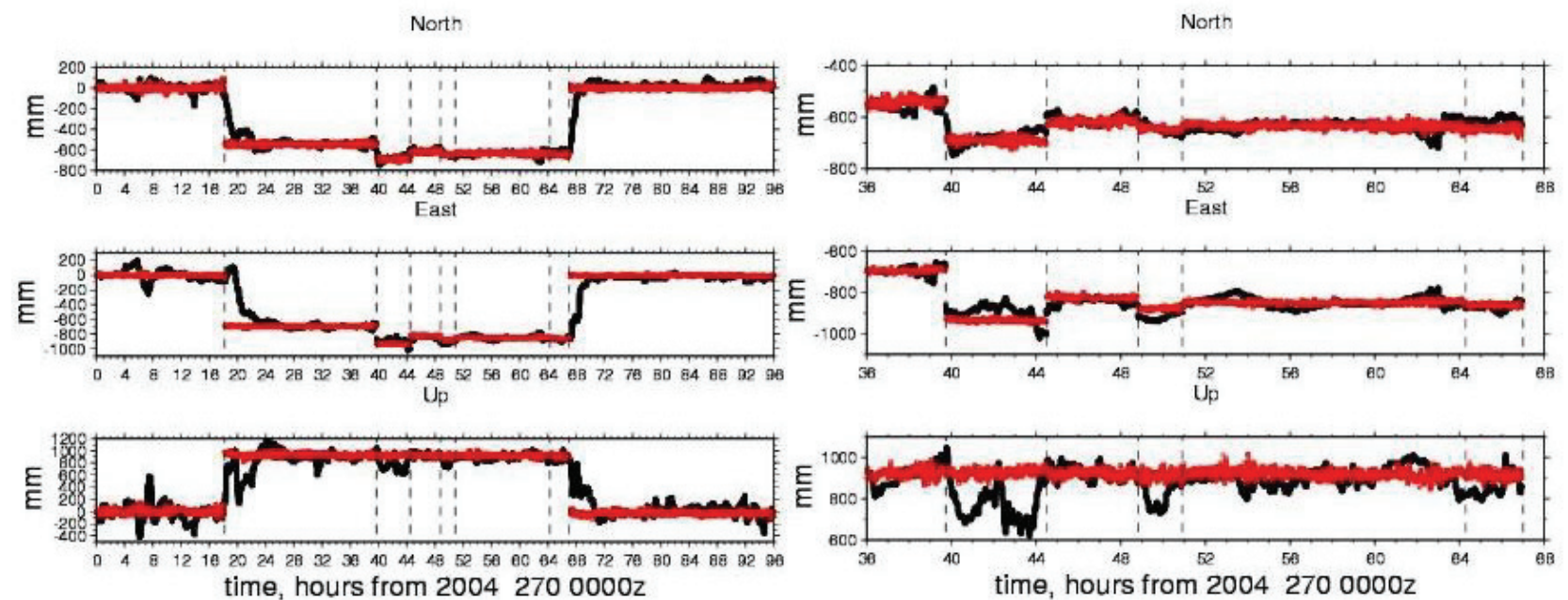

3DTracker, $\mathrm{L} 1$ and $\mathrm{Q}=10^{\wedge}-5$

\section{TRACK}

Figure 19: Comparison of displacement estimated by 3DTracker (black) and TRACK (red). Left hand side is data from the entire experiment. Right hand side is data from the measured translations. Integer ambiguities have be manually resolved in the TRACK solutions.

Using the same methods employed estimating the offset with the RTD experiment at Parkfield, the offsets are estimated using the TRACK data where the ambiguities have been resolved.

Table $6 . \quad$ Experimental offsets

\begin{tabular}{|l|l|l|l|l|}
\hline Time (hours) & \multicolumn{1}{|c|}{ East $(\mathbf{m m})$} & \multicolumn{1}{|c|}{ North $(\mathbf{m m})$} & \multicolumn{1}{c|}{ Magnitude } & \multicolumn{1}{c|}{ Measured (tape) } \\
\hline 40 & $-242.6 \pm 1.1$ & $-142.1 \pm 1.6$ & $-281.2 \pm 1.2$ & -280 \\
\hline 44 & $111.6 \pm 1.5$ & $72.3 \pm 2.2$ & $132.0 \pm 1.7$ & 141 \\
\hline 46 & $-52.8 \pm 1.8$ & $-29.6 \pm 2.6$ & $-60.4 \pm 2.0$ & -71 \\
\hline 51 & $27.3 \pm 1.6$ & $14.5 \pm 2.4$ & $30.9 \pm 1.8$ & 33 \\
\hline 64 & $-11.7 \pm 2.0$ & $-13.8 \pm 3.0$ & $-18.1 \pm 2.6$ & -16 \\
\hline
\end{tabular}


Table 7. Noise models of the data

\begin{tabular}{|l|l|l|}
\hline & \multicolumn{1}{|c|}{ East } & \multicolumn{1}{c|}{ North } \\
\hline White noise $(\mathrm{mm})$ & $<0.1$ & $<0.1$ \\
\hline Power law index $(\mathrm{n})$ & 1.56 & 1.54 \\
\hline Power law amplitude $\mathrm{mm} / \mathrm{yr}^{\mathrm{n} / 4}$ & 869 & 1284 \\
\hline Gauss Markov frequency, $\mathrm{rad} / \mathrm{yr}$ & 89800 & 96700 \\
\hline
\end{tabular}

Unlike the estimates of offset and uncertainty obtained for the 3DTracker results, the estimates for the TRACK data converged. However, the apparent precision, of better than $2 \mathrm{~mm}$ for the TRACK data and $3 \mathrm{~mm}$ for the 3DTracker data is a function of the Gauss Markov term in the noise model. The presence of the Gauss Markov term tends to whiten the noise spectra of the data at the low frequencies. Thus, with several hours of data taken before and after the offset, this allows for averaging which improves the apparent precision of the offsets. However, with only 10 minutes of data before and after an offset, the uncertainty is closer to $4 \mathrm{~mm}$.

\section{A snow melt event at Three Sisters; a comparison of several techniques}

In March of 2004, we observed an offset on the baseline HUSB to PMAR that is used to monitor the deformation of the Three Sisters volcano in Oregon. It is likely that the offset is nonvolcanic and is probably due to snow melting off the antenna at HUSB following a period of warm temperatures. The baseline is monitored using 3DTracker. In response to this signal, the RINEX files were shared with Nancy King (USGS, Pasadena) and Tom Herring (MIT). King used the data to estimate baseline change for each hour spanning the time of the event. She used the GAMIT software that ordinarily produces a solution based upon a 24 period. The input to the software was changed to permit estimates of the baseline vector to be made based upon 1 hour of data.

Tom Herring used TRACK to solve for baseline changes at the sampling interval of the data, which for this case is 30 seconds. 
North

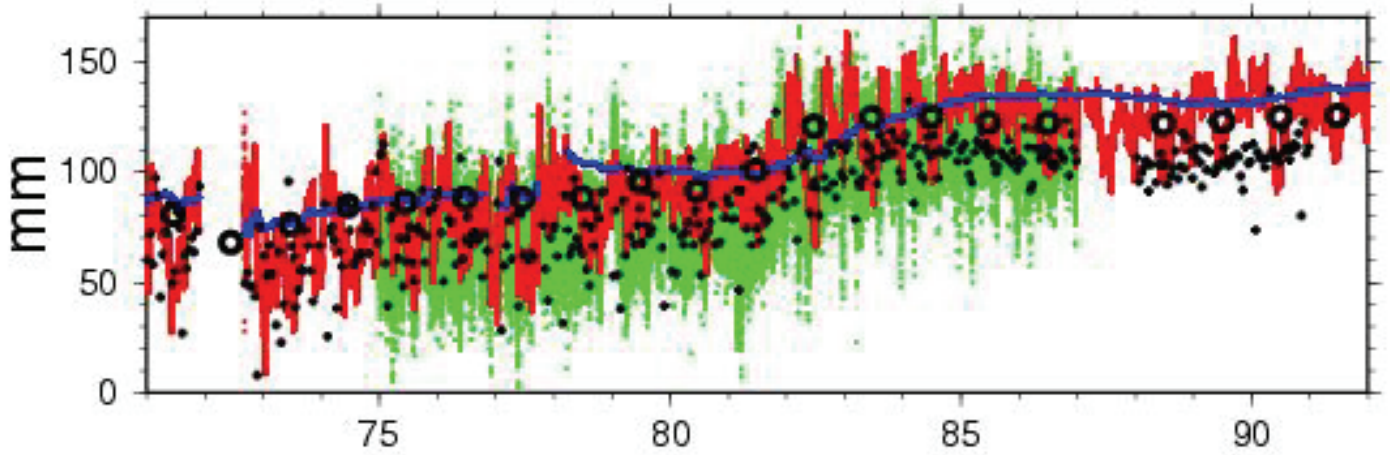

East

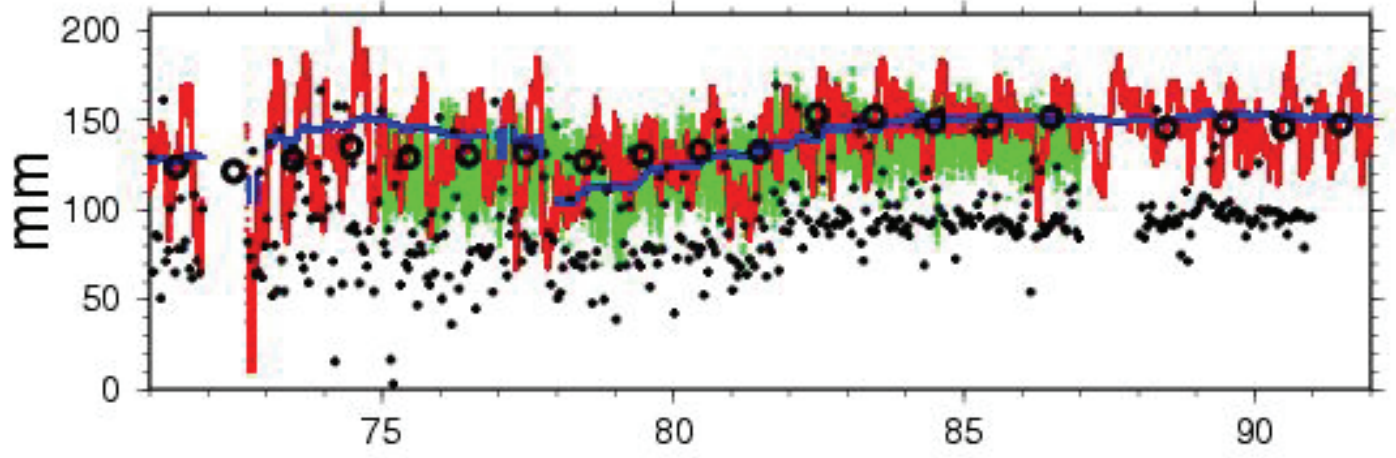

Up

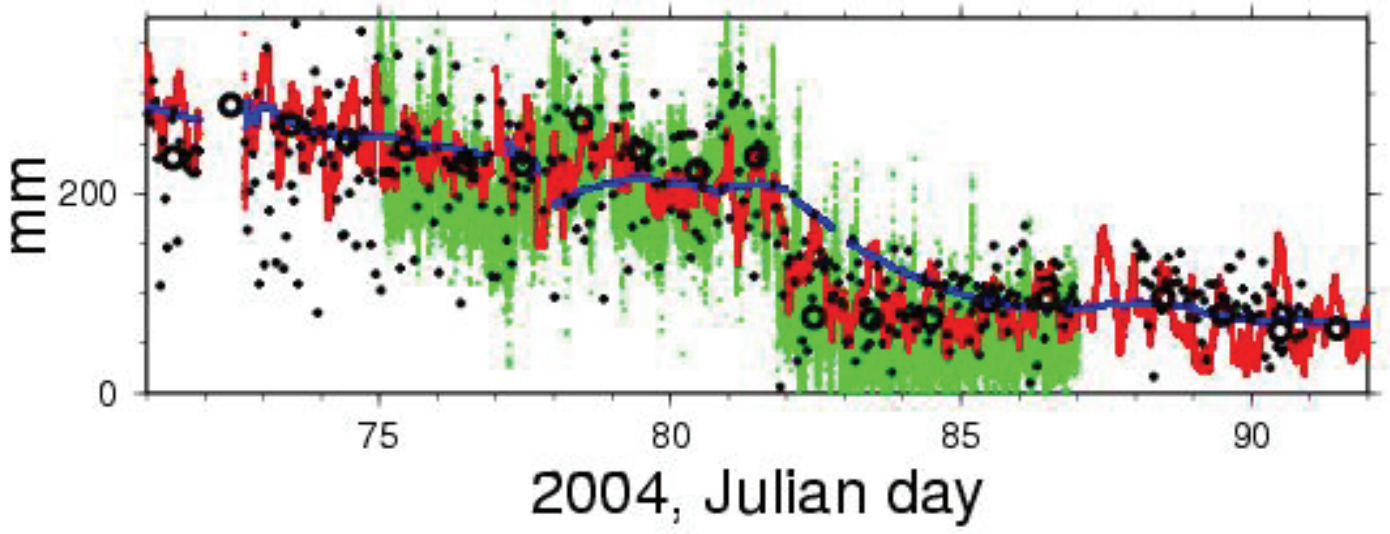

Figure 20. Time series of 15 days spanning a snow melt event 

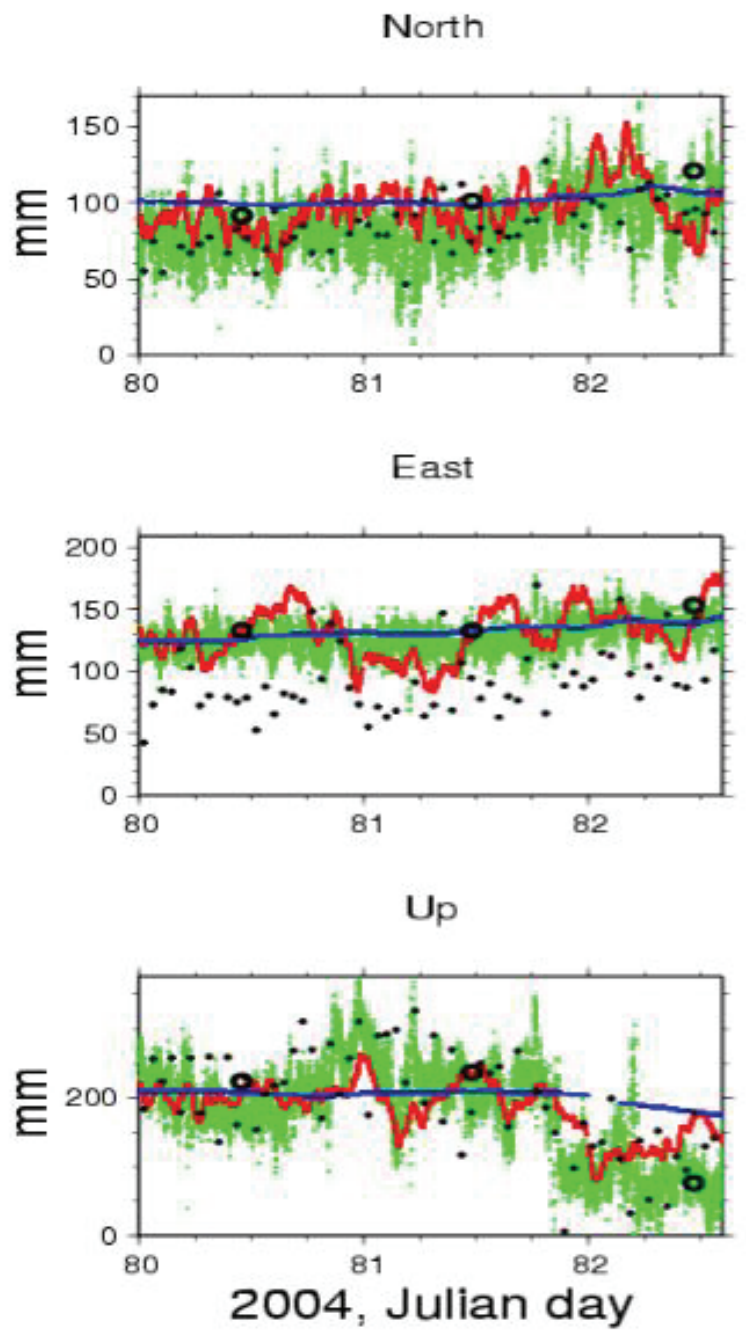

\section{GreenTrack $\quad$ Red 3DTracker Q=10^-7 Blue 3DTracker $\mathrm{Q}=10^{\wedge} 10$}

\section{Small dots GAMIT 1-hour Large circle GIPSY 24-hour}

Figure 21; $\quad$ Same as Fig 20 but for 2.5 days

Figures 20 and 21 show the estimate of baseline changes that span the snow melt event that occurred late on day 81 . The 24 hour solution indicates that the displacement was $20 \mathrm{~mm}$ north, 10 $\mathrm{mm}$ east and $175 \mathrm{~mm}$ up. Focusing on the vertical displacement shown in figure 21 indicates that 
with TRACK, one is able to determine that the snow melted rapidly, around 81.85 days. Although the change can be seen with 3DTracker with $\mathrm{Q}=10^{-7}$, the change is delayed by nearly 0.25 days. With the 1-hour GAMIT solutions, the change in not particularly obvious but could be better resolved with smoothing to reduce the scatter in the estimates. For all solutions (but especially with the GAMIT solutions) there is more scatter prior to the snow melting because the snow covered the antenna which tends to attenuate the GPS signal.

Qualitatively, the RMS scatter in the solutions are roughly the same for TRACK, 1-hour GAMIT solutions, and 3DTracker with $\mathrm{Q}=10^{-7}$; with $\mathrm{Q}=10^{-10}$, and for the 24-hour solutions, the RMS scatter is much less than the other three sets of solutions, but this is expected. However, where the offset is readily apparent in the 24-hour solutions, 3DTracker with $Q=10^{-10}$ shows the offset evolving over 3 days.

\section{Power spectra}

Another comparison of RTD and 3DTracker is through the spectra of power density (PSD). This was performed by Langbein and Bock (2004) for all of the Parkfield baselines that were analyzed by RTD over a 5 month interval. Mike Lisowski provide to me 30 days of 3DTracker data for an interval starting on Julian day 169 in 2004 for the HUSB to PMAR baseline. He computed solutions for Q's ranging from $10^{-5}$ to $10^{-10}$. The results are shown figure 22 .
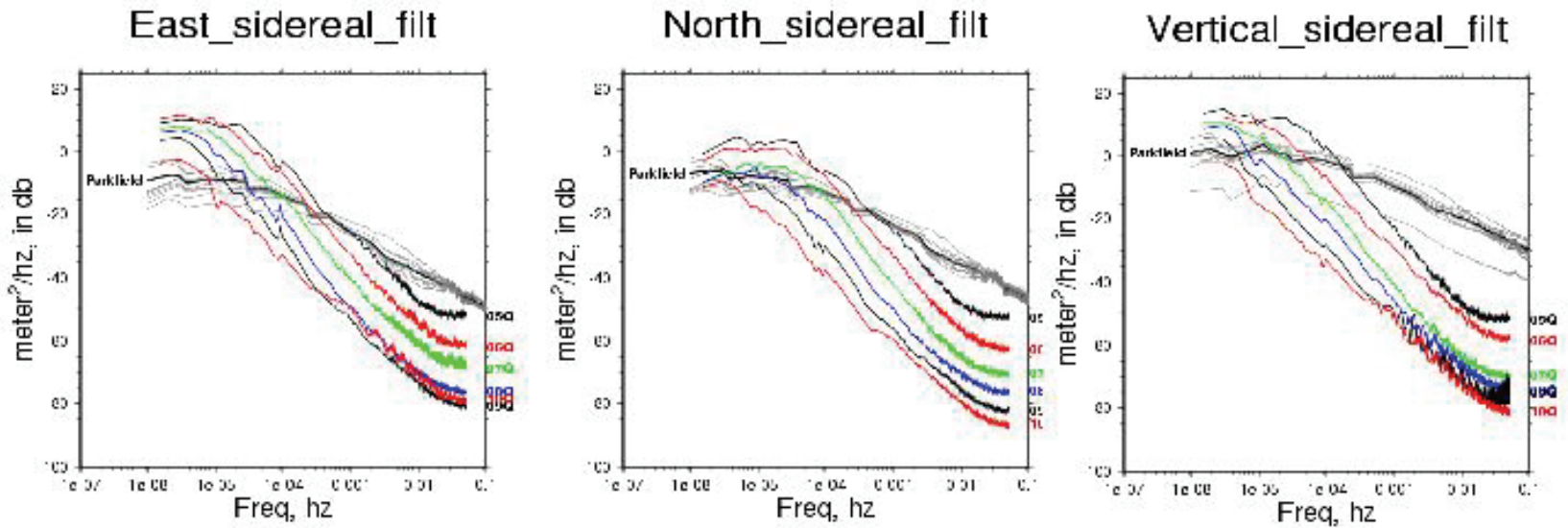

Figure 22: $\quad$ Power spectral density of 3DTracker data with different Q's compared with the Parkfield data using RTD. The $Q$ s are arranged such that $10^{-5}$ is on top and $10^{-10}$ is on the bottom.

For Parkfield, I present with the gray lines the PSDs for all of the baselines; the heavy black line represents the average PSDs shown in Langbein and Bock. The PSDs for 3DTracker are shown in color and identified with their Q's. At the highest frequencies, the PSDs suggest that 3DTracker has lower noise but, in reality, this reflects the heavy smoothing by the Kalman filter. At the lowest frequencies, the PSDs suggest that RTD has lower noise for most of the cases. However, a rigorous comparison of the power levels at the lowest frequencies can not be made at this time because of effects of finite data windows. The PSD for the RTD is better determined that those from 3DTracker since I've used a longer period to perform the analysis (5 months versus 1 month). 


\section{Discussion}

Several software packages that estimate positions from GPS at high sample rates have been evaluated in terms of accurately reproducing a simulated offset which might be seen in either tectonic or volcanic settings. I have examined 2 commercial products in detail, RTD from Geodetics and 3DTracker from Condor. Both of these packages estimate positions in real-time. In addition, I did a preliminary evaluation of TRACK, which is an outgrowth of GAMIT, and is freely available from MIT for research organizations to use. At this time, there has been no effort to make TRACK compatible for real-time processing. Although there are probably other vendors not mentioned in this report that produce software that computes positions at high sample rates, no effort has been made to seek out and test these products. I have limited myself to those systems to which I have immediate access.

The results presented in this report indicate that the 3 packages evaluated here can, to first order, reproduce the offsets that I have introduced by physically translating a GPS antenna. All three packages require some degree of input by the operator to minimize spurious deviations in the estimates of position. Once set-up, RTD requires the least input by the operator but, common to all GPS systems, spurious signals can appear due to multipath. With TRACK, manually fixing ambiguities eliminated spurious changes in position. Finally, with 3DTracker, by tinkering with the various settings, one can tune this software to measure offsets but this introduces other spurious signals.

In the body of the report, I present three tables where I have used the results from these software packages to estimate the size of the translations and compare those against the value I measured. The tables give uncertainties of these estimates which suggest that all three packages yield equivalent uncertainties of the order of 2 to $3 \mathrm{~mm}$. However, this equivalence is not the case and, in a "real-time" environment, we might have very limited data available to estimate the offset. The results presented for RTD are probably close to the situation that one might have operating in "real-time". That is, when an offset is visually detected, there might only be a few minutes of data after the offset to evaluate its size and error. With the results presented for TRACK, I noted that its precision in estimating the size of the offset based upon averaging the data over hours to one-day of data. Had we used only 20 minutes of data, I've re-estimated its precision to be closer to $4 \mathrm{~mm}$. However, comparing the $4 \mathrm{~mm}$ value for TRACK with the $2 \mathrm{~mm}$ precision from RTD is still not exactly correct; recall that the TRACK data were sampled at 30 seconds, but the RTD data were sampled at 1 second and decimated to 5 seconds. If RTD is used with the same sample rate as I had used with TRACK, the RTD precision is $3 \mathrm{~mm}$ which is not substantially different from that of TRACK.

The literature on the Internet for 3DTracker indicates that the software is more oriented to monitoring deformation over longer periods than the conditions that I simulated. In fact, Rutledge et al. (2001) state "We feel that since most monitoring projects are concerned with days rather than minutes, the relatively short initial converge time required for the triple-difference Kalman filter is an appropriate trade off for robust performance, ....". Thus, this software approximates the results achieved with the "research grade" software that we currently use to estimate positions in 24 hour batches. Here, in this report, I have adjusted 3DTracker so that it can measure rapid displacements, but, I knew a priori the correct answer, and I made the adjustments to the software to resolve the offsets. With real data, prior knowledge of the size and temporal character of the deformation will not be the case! 
The translation experiment described in this report is limited in its ability to truly test GPS hardware and software at seismic frequencies. To measure the response to translations over periods of less than 1 second will require significant engineering to either build or modify an apparatus.

Finally, the apparent $2 \mathrm{~mm}$ precision in estimating the offset with 3DTracker is not realistic due to the inadequacy of the noise model since that model does not account for spurious position changes and the presence of the Kalman filter smoothing the data at high frequencies. The inadequacy of the noise model can be shown with the following example. For the results presented above using L1 and a Kalman gain of $10^{-5}$ yields, for the offset at hour 40, an estimate of $-226.5 \pm$ $2.4 \mathrm{~mm}$. However, when a gain of $10^{-7}$ is used, the estimated offset becomes $-68.2 \pm 1.7 \mathrm{~mm}$. The actual offset is $-280 \mathrm{~mm}$. Neither estimate is close to the true offset and the estimate with the better "formal uncertainty" is wrong by a factor of 4 . On the other hand, with a gain of $10^{-3}$, the estimated offset is $-296.5 \pm 9.4 \mathrm{~mm}$ which is close to the actual offset.

\section{Conclusions and recommendations:}

- If we continue to use 3DTracker to monitor short-term deformation at Long Valley, we should be using the combination L1 and code data with a Kalman gain of $10^{-5}$ rather than the current settings of the Ionosphere Free "observable" and Kalman gain of $10^{-9}$. With this arrangement, it is possible to see offsets but, there will be many spurious offsets and displacements, too. Any signals seen with 3DTracker will need to be evaluated with other data sets including timing of large earthquakes at Long Valley and signals seen from nearby tilt and strain instruments. In many respects, this is not an optimal result. Under test conditions where we know that offsets have occurred; yes, we can measure these offsets using 3DTracker. However, these time-series can be very noisy with a few 10 s of centimeters in variation.

- When tuned with a Kalman gain of $10^{-9}$, 3DTracker seems to provides estimates of position in "real-time". This is not the case. With Kalman gains less than or equal to $10^{-7}$, the software could not resolve the times or the size of the displacements from this experiment. Instead, at best, it provides smoothed data, where, if tuned properly, could yield similar precision as we currently are getting using GIPSY. That is, 3DTracker could be used to detect deformation signals in the period of days to years. However, it is beyond the scope of this report to examine the long-term precision of 3DTracker other than to note that several other agencies which do use 3DTracker to monitor deformation. Since we currently use GIPSY and GAMIT to measure deformation over long periods, I do not see any reason to continue using 3DTracker for longterm monitoring.

- Both GIPSY and GAMIT have been modified to estimate position changes for each observed set of pseudo-range data. Theses software packages are able to detect and measure displacements provided by this experiment. However, if we use these software packages directly, the processing will not be in real-time.

- If real-time estimates of position changes are required, then several commercially systems are available. This includes RTD from Geodetics and RTG from NAVCOM; and there are likely other systems available.

- TRACK appears to have some advantages over many of the other software packages that are currently available for processing GPS data at high temporal resolution. Its primary advantage is that it is free. I suggest that the USGS acquire this software and gain experience using it.

Although it might not be appropriate to use this program for processing GPS data in "real-time", it certainly would be useful to process the GPS data "off-line". If continuous GPS observations 
are made available within 1 to 2 hours of their collection, then using TRACK to process these data could assist monitoring the position changes derived from GPS at sub-daily intervals. At longer time intervals, the daily solutions that we obtain using GIPSY/GAMIT are best. Of course, another alternative to TRACK is that, with time and encouragement, the modification of GIPSY by Kristine Larson could become another alternative to TRACK.

- If we chose to purchase a GPS system that delivers position estimates in real-time, the software should be examined closely before purchasing. Specifically, can the system resolve 1 centimeter, horizontal displacements from one sample to the next? And, at the 1-cm level, what is the false alarm rate? That is, how often are there apparent $1 \mathrm{~cm}$ changes that are not real?

Acknowledgments: I would like to thank the contributions by Mike Lisowski at CVO with his assistance and patience with my experiments at Long Valley. He set-up the software, made the RINEX files and assisted me with tuning 3DTracker. In addition, he provided to me the long runs of 3Tracker solutions which I used to compute the their power spectra. Adrian Borsa at USGSPasadena provided to me the results of the analysis by TRACK. Tom Herring and Nancy King provided me other solutions to the snow melting event on the Three Sisters. Yehuda Bock, Andy Snyder, and Stuart Wilkinson provided field support for this experiment. However, the interpretations and the conclusions stated in this report are mine.

\section{References Cited}

Reference, 2000, National water quality inventory-1998 Report, U.S. Environmental Protection Agency Report EPA-841-F-00-006, Washington D.C.

Bock, Y., R. M. Nikolaidis, P.J. De Jonge, and M. Bevis, Instantaneous geodetic positions at medium distances with the Global Positioning System, Jour. Geophys. Res. 105, 28,233-28,253, 2000.

Choi, K., A. Bilich, K. M. Larson, and P. Axelrad, Modified sidereal filtering; Implications for high-rate GPS positioning, Geophys. Res. Let., 31, doi:10.1029/2004GL021621, 2004.

GAMIT is described at: http://www-gpsg.mit.edu/ simon/gtgk/

Genrich, J. F. and Y. Bock, Rapid resolution of crustal deformation at short ranges with the Global Positioning System, Jour. Geophys. Res. 97, 3621--3269, 1992.

Langbein, J., Noise in two-color electronic distance meter measurements revisited, J. Geophys. Res., 109, 2004.

Langbein, J. and Y. Bock, High-rate real-time GPS network at Parkfield: Utility for detecting fault slip and seismic displacements, Geophys. Res. Lett., 31, 2004.

Langbein, J., J. R. Murray, and H.A. Snyder, Co-seismic and initial post-seismic deformation from the 2004 Parkfield, California Earthquake, observed by GPS, creepmeters, and borehole strainmeters, submitted, Bulletin of the Seismological Society of America, 2006

Larson, K. M., P. Bodin, and J. Gomberg, Using 1-Hz GPS data to measure deformation caused by the Denali fault earthquake, Science, 3000(5624), 1421-1424, 2003.

Remondi, B.W, and G. Brown, Triple Differencing with Kalman Filtering: Making it Work, GPS Solutions, 3, 58-64, 2000

Rutledge, D., J. Gnipp, and J. Kramer, Advances in real-time GPS deformation monitoring for landslides, volcanoes, and structure, in $10^{\text {th }}$ FIG International Symposium on deformation measurements, Session III, http://rincon.gps.caltech.edu/FIG10sym/ 2001. 
Zumberge, J.F, M.B. Heflin, D.C. Jefferson, M.M Watkins, and F.H. Webb, Precise point positioning for the efficient and robust analysis of GPS data from large networks, Jour. Geophys. Res., 102, 5005--5017, 1997. 